\title{
Approaches to Investigating the Protein Interactome of PTEN
}

\author{
Sarah L. Smith ${ }^{1}$ Andrew R. Pitt ${ }^{1,2}$ and Corinne M. Spickett ${ }^{1 *}$
}

${ }^{1}$ School of Life and Health Sciences, Aston Triangle, Aston University, B4 7ET, Birmingham, UK

${ }^{3}$ Manchester Institute of Biotechnology, University of Manchester, 131 Princess Street, Manchester. M1 7DN, UK

* Corresponding author Email: c.m.spickett@aston.ac.uk 


\section{ABSTRACT}

The tumour suppressor phosphatase and tensin homologue (PTEN) is a redox-sensitive dual specificity phosphatase with an essential role in the negative regulation of the PI3K-AKT signalling pathway, affecting metabolic and cell survival processes. PTEN is commonly mutated in cancer and dysregulation in the metabolism of $\mathrm{PIP}_{3}$ is implicated in other diseases such as diabetes. PTEN interactors are responsible for some functional roles of PTEN beyond the negative regulation of the PI3K pathway and are thus of great importance in cell biology. Both high-data content proteomics-based approaches and low-data content PPI approaches have been used to investigate the interactome of PTEN and elucidate further functions of PTEN. Whilst low-data content approaches rely on co-immunoprecipitation and western blotting, and as such require previously generated hypotheses, high-data content approaches such as affinity pull down proteomic assays or the yeast 2-hybrid system are hypothesis generating. This review provides an overview of the PTEN interactome, including redox effects, and critically appraises the methods and results of high-data content investigations into the global interactome of PTEN. The biological significance of findings from recent studies is discussed and illustrates the breadth of cellular functions of PTEN that can be discovered by these approaches.

\section{KEY WORDS}

Protein-protein interactions, global interactome, high-data content, affinity pull down, yeast 2hybrid, redox regulation. 
TEXT

\subsection{Introduction}

Phosphatase and tensin homologue (PTEN), also called mutated in multiple advanced cancers1 (MMAC-1) and tensin-like phosphatase-1 (TEP-1), is a 403 amino acid protein first identified in 1997 by three independent research groups ${ }^{1-3}$. PTEN has been identified as an antagonist of the AKT pathway through lipid phosphatase activity on phosphatidylinositol-3,4,5-phosphate ( $\left.\mathrm{PIP}_{3}\right)$ to form phosphatidylinositol-4,5-phosphate (PIP $)$, thus reversing the effect of phosphatidylinositol-3-kinase (PI3K) ${ }^{4}$. Negative regulation of the AKT pathway, through conversion of $\mathrm{PIP}_{3}$ to $\mathrm{PIP}_{2}$, modulates several metabolic processes, from lipogenesis to glycolysis as well as cell growth, proliferation and apoptosis ${ }^{5}$. In this way, PTEN activity determines important aspects of the cellular metabolic landscape, including dysfunction in a variety of diseases. PTEN is regulated both by post-translational modification (PTM), including phosphorylation and oxidation, and through important interactions with proteins such as protein kinase casein kinase 2 (CK2) and thioredoxin (Trx), highlighting the key importance of uncovering PTEN's interactome ${ }^{6,7}$.

Within the cell, large protein networks are composed of both highly and poorly connected systems that receive inputs and generate outputs ${ }^{8}$. Signal transduction is an essential cellular process, composed of sequential and controlled protein-protein interactions to modulate cellular processes, mediated by protein-binding domains ${ }^{9}$. Protein-protein interactions have notable effects, an example of which is activation/inactivation of enzymes through PTMs such as phosphorylation and oxidation, which can alter protein conformation, catalytic activity, and downstream interactions ${ }^{10-12}$. It is now widely accepted that a range of physiological and pathophysiological states alter protein-protein interactions (PPIs) of signalling proteins ${ }^{13,14}$. 
Advances in high-data content techniques for interactor identification, using both in vitro approaches, such as affinity pull-down assays, and in cellulo approaches, such as the yeast-2hybrid $(\mathrm{Y} 2 \mathrm{H})$ assay, have allowed progress in mapping PPIs of many signalling proteins, including PTEN. Comparisons of these two high-data content techniques noted relatively limited levels of PPI overlap between the different approaches ${ }^{8}$. This may result from high false positive and negative rates. In one study, affinity purification and $\mathrm{Y} 2 \mathrm{H}$ were estimated to have $40-80 \%$ false negative and $30-60 \%$ false positive rates ${ }^{15}$, while another on $\mathrm{Y} 2 \mathrm{H}$ reported a $25-45 \%$ false positive and a $75-95 \%$ false negative rate ${ }^{16}$. During a comparison of models of bait-prey interactions, a $39 \%$ false positive rate for affinity chromatography was described ${ }^{17}$. This issue is highlighted by the comparison of proteins identified as part of the yeast proteome, where 80,000 interactions are identified but only $3 \%(2,400)$ of these are supported by more than one method ${ }^{15}$. In addition, comparisons of independent $\mathrm{Y} 2 \mathrm{H}$ screens showed $<30 \%$ overlap due to the small fraction of the interactome detected per screen ${ }^{18,19}$. High false discovery rates continue to be an issue, with more recent papers focussing on the source and reduction of false positive PPIs ${ }^{20-25}$. However, it has been concluded that both techniques produce high-quality data that are complementary in nature 26. The limitations of both techniques, such as false positive hits, can in part be counteracted through the use of 'dry' and 'wet' techniques to validate a much smaller subset of the interactors identified. 'Wet' techniques include co-immunoprecipitation and western blotting through to affinity kinetic experiments such as surface plasmon resonance (SPR). 'Dry' techniques usually involve statistical and bioinformatics approaches where a confidence score is applied to identifying potential interacting proteins based on similarity in areas such as expression profile, function and sequence homology ${ }^{27}$. The use of co-immunoprecipitation and western blotting can also form the basis of low-data content investigations into singular protein-protein interactions. A cycle of high- 
data content hypothesis generation and low-data content hypothesis testing acts to strengthen interactome data sets, whilst also providing information on the function and wider implications of the protein-protein interaction.

While there are many excellent reviews on the structure, function and regulation of PTEN, as yet none have focused specifically on analysis of the approaches used to investigate its interactome, and the effect of modification and mutation on protein-protein interactions. The aim of this review is to bring together information on the different approaches that have been used to study PTEN interactors and the information obtained from them.

\subsection{Highlights}

- PTEN's membrane recruitment and phosphatase activity are regulated by PPIs.

- High-data density methods such as $\mathrm{Y} 2 \mathrm{H}$ and affinity pull down assays have been utilised successfully to identify protein interactors of PTEN.

- Identified interactors have been validated using techniques such as coimmunoprecipitation and western blotting.

- Functional validation of a small subset of interactors has been elucidated using in vitro and in situ assays.

- Mutation and oxidation of PTEN inhibits phosphatase activity and alters PPIs.

\subsection{Structure, Function and Regulation of PTEN}

\subsection{The Structure and Function of PTEN}

In order to appreciate the PPIs of PTEN, in particular the sites of interaction within PTEN and their effects on its function, it is essential to have an overview of its structure; this is also important 
for the design of proteomic approaches to investigate PPIs. PTEN has two major domains, an Nterminal phosphatase domain and a C-terminal membrane binding domain ${ }^{28}$. The N-terminal phosphatase domain shows homology to the dual-specificity phosphatase (DUP) Vaccinia H1related (VHR) with conserved stretches of amino acids in the phosphate binding (P) loop, the TI loop and the WPD loop ${ }^{29}$ (Figure 1) which are all essential for catalysis and conformation ${ }^{28}$. The P loop contains the protein tyrosine phosphatase (PTP) conserved HCXXGXXR motif essential for phosphatase activity, whereby the catalytic cysteine (C124) acts as a nucleophile through which the phosphoryl group is transferred, forming a thiol phosphate intermediate during catalysis ${ }^{30-34}$. The WPD-loop, which contains an FED (F90-E91-D92) motif, is also called the movable loop due to its ability to move into the active site on substrate binding (known as a closed conformation) ${ }^{34}$. This movement allows D92 to participate in the hydrolysis of the cysteine thiol phosphate intermediate ${ }^{32,34}$. The key difference between the active site of PTEN and other PTPs is the increased width of the active site pocket, owing to a 4-amino acid insertion to the TI loop ${ }^{28}$. This insertion allows accommodation of PTEN's physiological substrate phosphoinositide-3,4,5phosphate $\left(\mathrm{PIP}_{3}\right)$, which is larger than those of most other PTPs and DUPs ${ }^{28}$. Recent evidence has shown residues T167 and I168 to be essential for substrate specificity ${ }^{35}$.

The C-terminal domain can be further subdivided into the C2 domain, the C-terminal tail and the PDZ motif. The $\mathrm{C} 2$ domain is a calcium binding domain which permits binding to phospholipids, inositol polyphosphates and phosphotyrosine domains (PTB), allowing the association of PTEN and the cell membrane ${ }^{28,36,37}$. The $\mathrm{C} 2$ domain has extensive contact with the phosphatase domain and so assists PTENs catalytic activity through a productive orientation of the active site at the membrane $28,38,39$. The C-terminal tail is an intrinsically disordered region (IDR) that contains a number of binding motifs and sites of post-translational modification, and is 
a key part of the protein for mediating PPIs ${ }^{40}$. Aberrant post-translational modification or mutation of this region may be important in disease, and it may also, therefore, present a new drug target. This is discussed further in the sections below. The C-terminal tail contains proline/serine/threonine/glutamic acid rich (PEST) sequences related to half-life and stability ${ }^{41}$, 42. A region of inhibition through phosphorylation is found in the C-terminal tail which includes residues T366, S370, S380, T382, T383 and S385 ${ }^{43-45}$. Phosphorylation of the C-terminal tail reduces both the phosphatase activity as well as PTEN's lipid membrane affinity through a conformational change, whereby the tail interacts with the $\mathrm{C} 2$ domain ${ }^{45}$. This closed conformation blocks membrane binding as well as the active site ${ }^{46}$. Auto-dephosphorylation removes the phosphates from T366 and S370 to allow phosphatase activity ${ }^{46,47}$. The three terminal residues of the C-terminal domain, T401, L402 and V403, form the PDZ-motif, a typical module where protein-protein interactions can occur ${ }^{28,48-51}$.

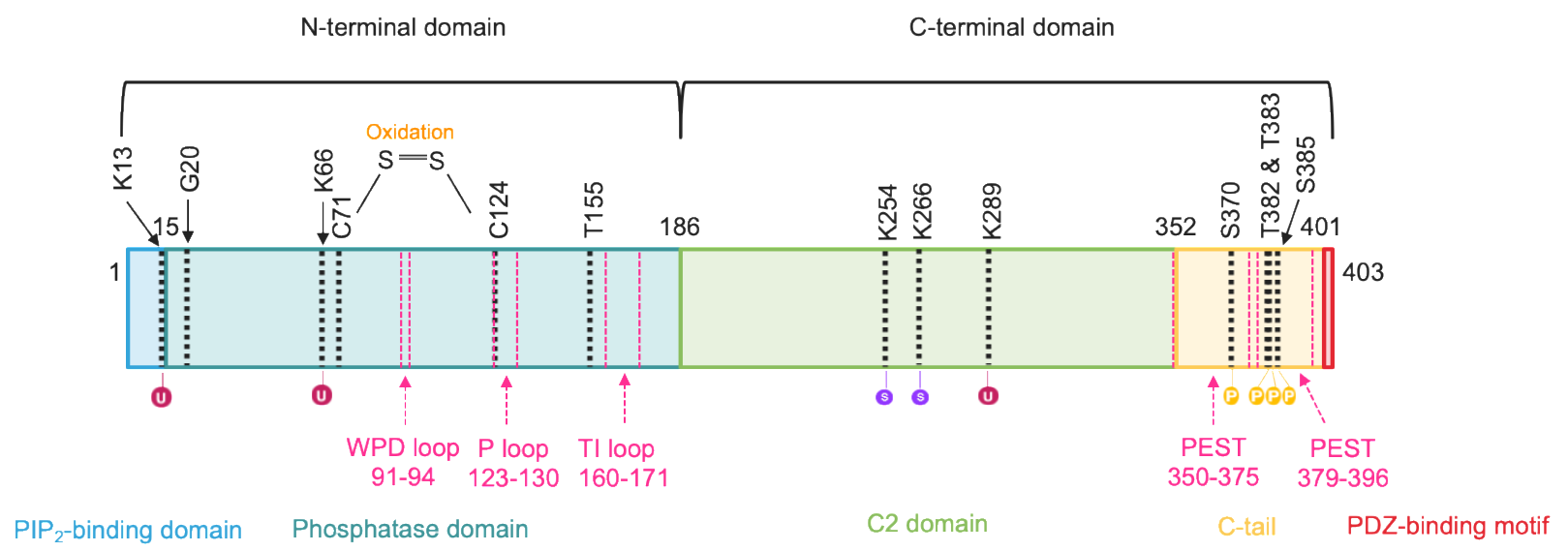

Figure 1. The N- and C- terminal domains of PTEN. The modular structure of PTEN shows Nterminal and C-terminal domains. The N-terminal $\mathrm{PIP}_{2}$ binding domain (blue) contains $\mathrm{K} 13$, which can be modified by ubiquitinylation (U). The phosphatase domain (dark green) contains the WPD loop, P loop and TI loop. Within the phosphatase domain is the resolving C71 and catalytic C124, 
which on oxidation form a disulfide bond. Two residues, G20 and T55, are mutated in two of the high-data content studies included in this review. The C2 domain (green) contains K254, K266 and K289 which are amino acids modified by ubiquitinylation (U) and SUMOylation (S). The Cterminal tail (yellow) contains two PEST sequences, as well as four residues which can be modified by phosphorylation (P); S370, T382, T383 and S385. The PDZ-binding motif is shown in red.

\subsection{Isoforms of PTEN}

Two extended isoforms of PTEN have been identified: PTENa (or PTEN-long, PTEN-L) with an additional $173 \mathrm{~N}$-terminal amino acids, and PTEN $\beta$ with an additional $146 \mathrm{~N}$-terminal amino acids ${ }^{52-54}$. In comparison to canonical PTEN, these translational isoforms vary in their subcellular location.

PTEN $\alpha$ is localised in mitochondria, with involvement in the maintenance of mitochondrial structure and function, including the promotion of energy production ${ }^{52}$. Recently, PTEN $\alpha$ has been reported as a protein phosphatase for ubiquitin, acting to inhibit mitophagy ${ }^{55}$, the selective autophagy to remove damaged and impaired mitochondria where there is loss of inner mitochondrial membrane potential that is essential for energy production ${ }^{56,57}$. This has important implications in Parkinson's disease, the pathogenesis of which is linked to defective mitophagy ${ }^{55}$. A further study reported PTEN $\alpha$ as a membrane permeable and secreted form of PTEN ${ }^{53}$. As an exogenous agent, PTENa was found to be able to enter other cells and downregulate PI3K signalling in the same manner as canonical PTEN ${ }^{53}$.

PTEN $\beta$ is found in the nucleolus, associated with the phosphoprotein nucleolin ${ }^{54}$. Dephosphorylation of nucleolin by PTEN $\beta$ downregulates ribosomal deoxyribonucleic acid (rDNA) transcription and, therefore, ribosomal biogenesis and cell proliferation ${ }^{54}$. Nucleolin 
upregulates cell proliferation and through the identification of increased growth in PTEN $\beta$ knockout cells, PTEN $\beta$ has been proposed to control cell proliferation through the downregulation of rDNA synthesis ${ }^{54}$. A recent study reported that PTEN $\alpha$ and PTEN $\beta$ promote tumorigenesis through maintenance of cancer promoting signature ${ }^{58}$. Whilst this review focuses on canonical PTEN, it is important to note that differences would be expected in the interactomes of the different PTEN isoforms, not only due to the N-terminal extensions and the additional corresponding binding domains, but also differences in extra- and subcellular locations.

\subsection{PTEN as a Tumour Suppressor and a Metabolic Regulator}

The biological functions of PTEN are diverse and have been reviewed previously ${ }^{59-61}$. Its role in signalling pathways provides an initial pointer to its likely interactors, and helps to inform the choice of proteomics approaches to investigate them. PTEN was initially identified as a tumour suppressor through demonstration of its role as a down-regulator of AKT signalling pathways through reduction of the cellular levels of $\mathrm{PIP}_{3}{ }^{4}$. Recruitment of AKT to the cell membrane occurs through its pleckstrin homology domain $(\mathrm{PH})$, which binds to $\mathrm{PIP}_{3}{ }^{62}$. This binding allows the activation of AKT through phosphorylation at T308, a catalytic T-loop residue, by phosphoinositide-dependent protein kinase 1 (PDK1) ${ }^{63}$. PDK1 is recruited through binding via its $\mathrm{PH}$ domain to $\mathrm{PIP}_{3}{ }^{64}$. Maximal activity of AKT is seen when $\mathrm{S} 473$, a C-terminal residue, is phosphorylated by mammalian target of rapamycin complex 2 (mTORC2) preserving the activation state of AKT through stabilisation of T308 phosphorylation ${ }^{65-67}$. mTORC2 is activated by phosphorylated AKT (pAKT), giving a positive feedback loop ${ }^{66}$. The activation of AKT and its regulation by PTEN have a wide variety of downstream effects from cell survival to metabolism (Figure 2) ${ }^{68-70}$. 


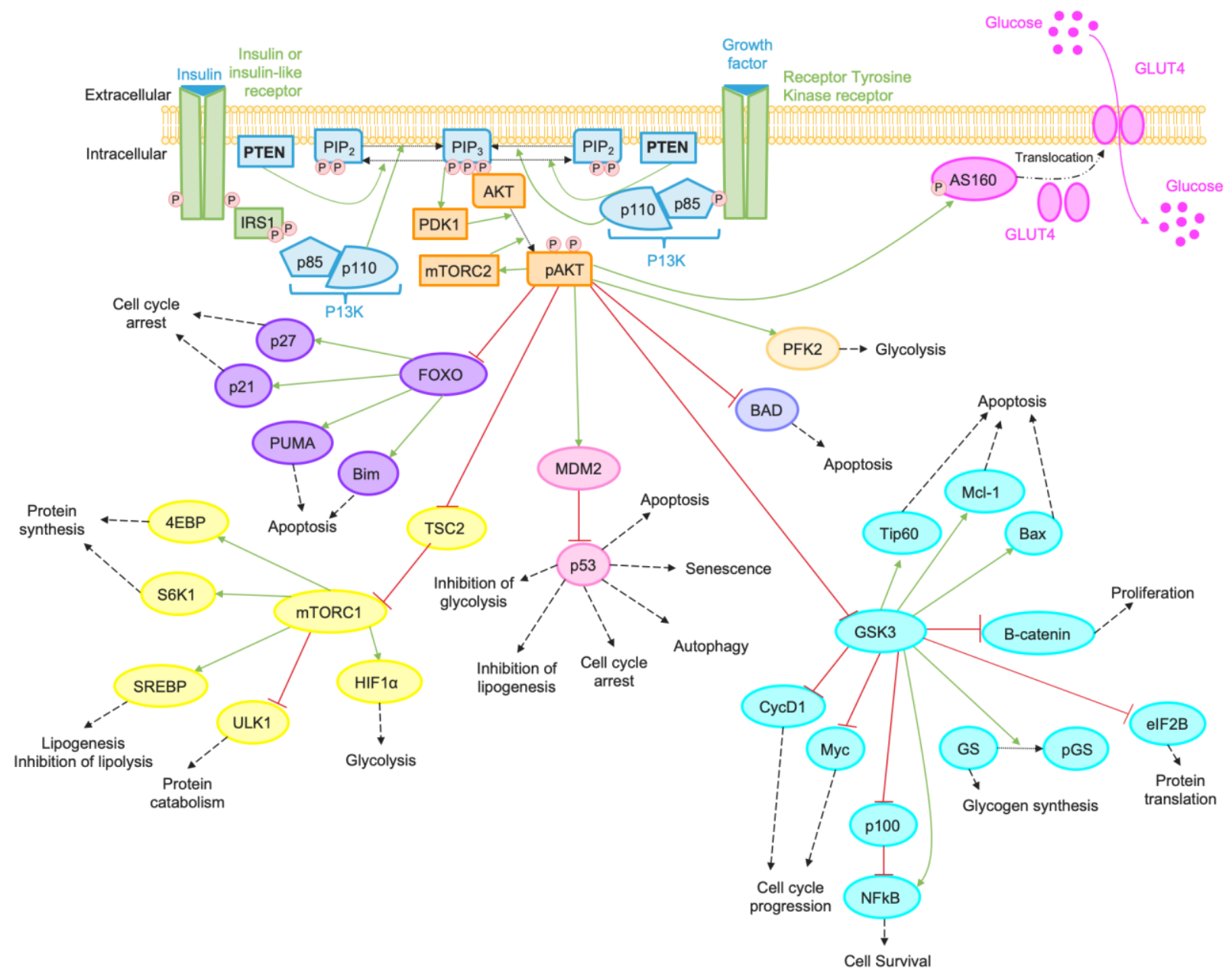

Figure 2. Schematic of PTEN's role in and the downstream effects of the AKT pathway. The pathway is activated at the cell membrane; downstream, phosphorylated AKT signals to FOXO, MDM2, GSK3 and BAD nodes to regulate cell survival versus cell death, while TSC2, mTORC1, PFK2 and AS160 nodes have more impact on metabolism.

Table 1. The effect of an increase in PIP 3 on metabolism and cell survival \begin{tabular}{|l|l}
\hline Metabolic effects: & Cell survival effects:
\end{tabular} 


\begin{tabular}{|l|l|}
\hline 1. Protein synthesis & $\begin{array}{l}\text { 1. Cell cycle progression \& inhibition of } \\
\text { cell cycle arrest }\end{array}$ \\
2. Lipogenesis & 2. Cell survival \& inhibition of apoptosis \\
3. Inhibition of lipolysis & 3. Proliferation \\
4. Glycogen synthesis & \\
5. Glucose uptake & \\
6. Glycolysis \\
7. Suppression of protein catabolism \\
(autophagy)
\end{tabular}

Figure 2 outlines how the PI3K-PTEN regulatory balance plays an important role in cell survival and proliferation via control of AKT signalling and the linked regulatory nodes of GSK3, mTORC1, FOXO and p53 ${ }^{71-80}$. In addition to these large networks, AKT also mediates smaller networks, such the activation of PFK2 and AS160 ${ }^{81-83}$ (Figure 2). As PTEN is the key regulator in the cellular levels of $\mathrm{PIP}_{3}$, PTEN activity has many physiological consequences, summarized in Table 1. Activation of insulin receptors through binding of insulin and insulin-like growth factors results in the activation of signal transduction of pathways involved in the regulation of both glucose and lipid metabolism ${ }^{5,68}$. Increased $\mathrm{PIP}_{3}$ upregulates protein, glycogen and lipid synthesis as well as glycolysis and glucose uptake, whilst downregulating lipolysis and protein catabolism. Loss of regulation by PTEN leads to improved insulin sensitivity, reducing the risk of type 2 diabetes, although also increasing the risk of obesity ${ }^{5,84}$. Activation of receptor tyrosine kinases (RTKs) with growth factors leads to recruitment of PTEN and its modulation of downstream effects regulating cell survival. These include cell cycle progression and inhibition of cell cycle arrest with inhibited apoptosis and an increase in cell survival and proliferation, highlighting the important tumour suppressive function of PTEN. Alterations in both cell survival mechanisms and 
metabolic processes are essential for tumour progression ${ }^{80}$. Tumour suppression by PTEN is apparent from the effects of loss or mutation of PTEN leading to catalytic inhibition, which results in neoplastic disorders such as Cowden's syndrome ${ }^{85,86}$.

\subsection{Regulation of PTEN's activity, interactions and cellular localization by post-}

\section{translational modification}

PTEN can be regulated through both genetic and non-genetic means, the mechanisms of which have previously been reviewed ${ }^{87,88}$. Genetic regulation of PTEN includes genetic alterations, epigenetic silencing and transcriptional and post-transcriptional regulation ${ }^{59,89,90}$. Non-genetic regulation of PTEN's activity includes post-translational modification (PTM) such as phosphorylation, oxidation, reduction, nitrosylation, and ligation with ubiqituin and small ubiquitin like modifier (SUMO) ${ }^{6,7,89,91-93}$. PTMs can also affect PPIs, as discussed in Section 2.5, and PPIs themselves can regulate PTEN ${ }^{61,88,94}$.

Phosphorylation at the C-terminal tail by protein kinase CK2 prevents the recruitment of PTEN to a multimeric complex at the cell membrane through conformational changes acting to mask the PDZ-motif ${ }^{6}$. The resulting 'closed' structure of PTEN prevents access to PIP 3 , removing PTEN's modulation of the AKT pathway ${ }^{6,95}$. It has been shown in human $\mathrm{T}$ cell acute lymphoblastic leukemia cells that protein CK2 phosphorylation of PTEN leads to constitutive activation of the AKT pathway through stabilisation of PTEN's expression and inhibition of PTEN's catalytic activity ${ }^{96}$. The acidic nature of the amino acids flanking Y383, as part of PTEN's C-terminal tail, suggested similarities to PTEN's physiological substrates and led to a hypothesis that Y383 could be a site of auto-dephosphorylation ${ }^{43,97}$. As protein kinase CK2 is constitutively active, 
dephosphorylation of PTEN may be a key mechanism regulating its activity ${ }^{6,98}$, similarly to MAPK signalling pathways ${ }^{99}$.

In addition to phosphorylation, oxidation of PTEN is an important mechanism of regulation and results in its inactivation ${ }^{7}$. Oxidation of the catalytic cysteine $(\mathrm{C} 124)$ by oxidizing species such as hydrogen peroxide $\left(\mathrm{H}_{2} \mathrm{O}_{2}\right)$ and hypochlorous acid $(\mathrm{HOCl})$ have been documented to cause doseand time-dependent inactivation of PTEN ${ }^{7,100}$. Whilst free cysteine residues in aqueous solution have a calculated $\mathrm{pK}_{\mathrm{a}}$ of 8.6 , due to the nature of the flanking amino acids the calculated $\mathrm{pK}_{\mathrm{a}}$ of $\mathrm{C} 124$ is 4.5 . This lower $\mathrm{pK}_{\mathrm{a}}$ means the thiol group (-SH) exists as a thiolate ion $\left(-\mathrm{S}^{-}\right)$at physiological $\mathrm{pH}^{30,101}$; thiolate ions have increased reactivity, a property that is essential for nucleophilic catalysis, but also result in an increased susceptibility to oxidation ${ }^{101-103}$. On oxidant exposure, the thiolate ion is oxidised to sulfenic acid (-SOH), which is capable of rapidly forming disulfide bonds with proximal cysteines; in the case of PTEN this is the so called resolving cysteine, $\mathrm{C} 71^{7}$. The formation of this intramolecular disulfide bond inactivates PTEN, and as with other phosphatases is believed to protect it from further (over-)oxidation, which can be reversed by reduction with glutathione (GSH), dithiothreitol (DTT) or redox proteins such as thioredoxin (Trx) and glutaredoxin (Grdx), which all restore catalytic activity ${ }^{7,91,104}$. A further element to the redox regulation of PTEN includes S-nitrosylation of cysteine thiol groups by $S$-nitrosocysteine (CSNO), leading to the formation of a protein mixed disulfide and reversibly inhibiting PTEN's catalytic activity ${ }^{105}$. In addition, through the ubiquitin protease system (UPS), nitric oxide (NO) induces PTEN degradation ${ }^{93}$.

The reversible ligation of ubiquitin and SUMO to PTEN controls not only protein stability, but also cellular localization 92, 106 . Ubiquitination of PTEN is mediated by several E3 ubiquitin ligases, including NEDD4-1 and WWP2 ${ }^{107}$. Notable sites of ubiquitination on PTEN include K13, 
K66 and K289 92,108. Polyubiquitination of PTEN is linked to degradation through the ubiquitin proteasome system (UPS), whilst monoubiquitination leads to nuclear import 92, 107, 109. SUMOylation of PTEN at K254 and K266 in the C2 domain promotes binding to the cell membrane, facilitating PTEN activation and the downregulation of the AKT pathway ${ }^{110}$. SUMOylation of PTEN is also associated with nuclear retention and DNA repair during genotoxic Stress ${ }^{111,112}$.

\subsection{Protein-Protein Interactions with PTEN}

The mechanisms by which the membrane binding, cellular location and catalytic activity of PTEN is regulated by PTMs, facilitated by or altering protein-protein interactions (PPIs), as described in section 2.4, highlights the importance of the interactome of PTEN. The role of PPIs

in the regulation of PTEN has previously been reviewed ${ }^{61,88,94}$, which illustrates the range of effects of PPIs. At the time of writing, BioGrid ${ }^{113}$ reports 755 published interactions with PTEN (Supplementary table 1), corresponding to 551 unique interactors. The associated gene ontology (GO) biological processes of these interacting proteins encompasses many different processes including those involved in cell signalling, cell survival and immune response, as well as organ function and the central nervous system (Supplementary table 2) ${ }^{113}$. An additional interaction database, IntAct, describes 227 binary interactions with PTEN, by a total of 95 interactors (Supplementary table 3) ${ }^{114}$. IntAct is one of the partners of BioGRID and so would be expected to contain all of the interactions reported by BioGRID (Supplementary table 1). However, a small number of additional PTEN interactions reported by IntAct are not found within the BioGRID dataset. 


\subsection{Methods to Identify PTEN Interacting Proteins}

High-data content investigations into protein-protein interactions generate hypotheses, allowing new directions and lines of enquiry to be discovered, helping to reveal previously unknown aspects of PTEN's interactions and function, In contrast, low-data content investigations are hypothesisdriven and are useful for providing detailed mechanistic information on individual PTEN interactions and validating high-data content output. Methods for low-data content, hypothesisdriven investigations include co-immunoprecipitation and western blotting, whilst methods for high-data content, hypothesis-generating investigations include affinity pull down assays and the yeast-2 hybrid assay. Co-immunoprecipitation and western blotting are also used in high-data content investigations as validation steps. Whilst the yeast-2 hybrid assay was originally a lowdata content method used on a small scale for single proteins, this method has been scaled up to become high-throughput ${ }^{115,116 .}$

Important examples of interactors studied by hypothesis driven, low-data content investigations into PTEN's interactome are thioredoxin (Trx), peroxiredoxin (Prdx-1) and DJ-1. As discussed in section 2.4, PTEN's phosphatase activity is inactivated by oxidation through intramolecular disulfide bond formation ${ }^{7}$. Two known cellular antioxidants, Trx and GSH, were tested for their ability to reduce this disulfide bond by monitoring PTEN mobility shifts induced by disulfide bond formation in non-reducing gels, with Trx identified as the more efficient PTEN reductant ${ }^{7,117}$. It was noted that the significant change in mobility on formation of the disulphide suggests this induces some conformation change in the protein, as well as the potential change in charge state. There have since been further in vitro and in vivo investigations into the relationship of Trx and PTEN ${ }^{118-121}$. Prdx-1 is a peroxidase isoform with a role in redox regulation through reduction of oxidants such as hydrogen peroxide $\left(\mathrm{H}_{2} \mathrm{O}_{2}\right){ }^{122}$. Increased PTEN oxidation was seen with loss of 
Prdx-1 and an interaction was confirmed through western blotting ${ }^{123}$. Under mild oxidative stress, using a $25 \mu \mathrm{M} \mathrm{H}_{2} \mathrm{O}_{2}$ treatment, PTEN's lipid phosphatase activity for $\mathrm{PIP}_{3}$ was protected by Prdx$1^{123}$. This was lost under conditions of higher oxidative stress, with a $500 \mu \mathrm{M} \mathrm{H}{ }_{2} \mathrm{O}_{2}$ treatment, where there was decreased PTEN-Prdx-1 binding, which is further discussed in section $4.4{ }^{123}$. DJ1 is an oncogenic protein with a role in tumourigenesis and cancer progression ${ }^{124,125}$. DJ-1 was identified as a negative regulator of PTEN through the P13K pathway using Drosophila as a model for mammalian systems ${ }^{126}$. Additionally, transient transfection of PTEN and/or DJ-1 in mouse fibroblasts provided evidence that DJ-1 rescued the cells from PTEN-induced apoptosis ${ }^{126}$. More recently, this has been expanded to investigate whether activation of the AKT pathway was the cause of DJ-1's oncogenic effects ${ }^{127}$. Increased DJ-1 expression gave decreased PTEN levels resulting in accelerated colorectal cancer and as such, DJ-1 has been proposed as a novel biomarker for prognosis in colorectal cancer ${ }^{127}$.

To date, there are only 8 published studies specifically investigating PTEN's interactome using eukaryotic, non-genetic and high-data content methods (Table 2). Each of these studies utilised either the yeast2hybrid (Y2H) assay or affinity pull-down assays with a PTEN fusion protein to identify potential interactors (between 12 and 400 per study), but only a select few (1-4) were taken forward for validation ${ }^{128-135}$. Figure 3 shows the different experimental approaches taken by each of these high-data content investigations. One group expanded the search to identify redoxdependent alteration in PPI through in vitro affinity capture with reduced and oxidised PTEN ${ }^{134}$. Of the 97 interactors identified in this study, 4 were further investigated, and of these, the extent of interaction of 3 proteins, peroxiredoxin $1(\operatorname{Prdx} 1)$, thioredoxin $(\operatorname{Trx})$ and annexin A2 (Anxa2), were found to be dependent on the redox status of PTEN ${ }^{134}$. In another study, interactors that had higher affinity for the cancer associated G20E mutant of PTEN were investigated, and 1 specific 
G20E interactor, calumenin (CALU) was identified ${ }^{132}$. The systematic approaches to investigating PTEN PPIs of nuclear-localized PTEN, and broader investigations into PPIs of tyrosine phosphatases and their involvement in protein networks, have been recently extensively reviewed ${ }^{136-139}$ so have not been described in detail in this section; neither have the genetic techniques of PTEN PPI identification, which have also been reviewed recently ${ }^{140-142}$. 
Table 2: Summary of the High Data Density Investigations into PTEN's Interactome

\begin{tabular}{|c|c|c|c|c|c|c|c|}
\hline $\begin{array}{l}\text { Publication } \\
\text { Date }\end{array}$ & Authors (DOI) & Condition & $\begin{array}{l}\text { Isolation } \\
\text { Method }\end{array}$ & $\begin{array}{l}\text { Identification } \\
\text { Method }\end{array}$ & $\begin{array}{l}\text { Validation } \\
\text { Method }\end{array}$ & $\begin{array}{l}\text { No. of } \\
\text { Potential } \\
\text { Interactors }\end{array}$ & $\begin{array}{l}\text { No. of } \\
\text { Validated } \\
\text { Interactors }\end{array}$ \\
\hline 2004 & Gorbenko et al. ${ }^{128}$ & $\mathrm{~N} / \mathrm{A}$ & $\mathrm{Y} 2 \mathrm{H}$ & $\begin{array}{l}\text { Restriction } \\
\text { analysis } \\
\text { DNA } \\
\text { sequencing }\end{array}$ & Mating Assay & 43 & 1 \\
\hline 2005 & $\begin{array}{l}\text { Crockett et al. }{ }^{130} \\
(\underline{\mathbf{1 0 . 1 0 0 2 / p m i c . 2 0 0 4 0 1 0 4 6}})\end{array}$ & $\mathrm{N} / \mathrm{A}$ & $\begin{array}{l}\text { APD } \\
\text { In silico }\end{array}$ & LC-MS/MS & $\begin{array}{l}\text { In vitro and in } \\
\text { silico data } \\
\text { alignment }\end{array}$ & $\begin{array}{l}\text { In vitro: } 79 \\
\text { In silico: } 349\end{array}$ & 42 \\
\hline 2007 & $\begin{array}{l}\text { Herlevsen et al. }^{131} \\
\underline{\text { (10.1016/j.bbrc.2006.11.067) }}\end{array}$ & $\begin{array}{l}\text { Human } \\
\text { Bladder } \\
\text { Cancer }\end{array}$ & APD & LC-MS/MS & $\begin{array}{l}\text { Reciprocal } \\
\text { APD } \\
\text { Western Blot }\end{array}$ & 400 & 1 \\
\hline 2008 & $\begin{array}{l}\text { Ahn et al. }{ }^{135} \\
(\underline{\mathbf{1 0 . 1 0 4 2 / B J 2 0 0 7 1 4 0 3})}\end{array}$ & $\mathrm{N} / \mathrm{A}$ & APD & LC-MS/MS & $\begin{array}{l}\text { Co-IP } \\
\text { Western Blot } \\
\text { Fluorescence } \\
\text { Microscopy } \\
\text { RT-PCR }\end{array}$ & 93 & 1 \\
\hline 2010 & $\begin{array}{l}\text { Gorbenko et al. }{ }^{129} \\
\underline{(10.1007 / \mathrm{s} 11010-009-0312-1})\end{array}$ & $\mathrm{N} / \mathrm{A}$ & $\mathrm{Y} 2 \mathrm{H}$ & $\begin{array}{l}\text { Restriction } \\
\text { analysis DNA } \\
\text { sequencing }\end{array}$ & $\begin{array}{l}\text { Co-IP } \\
\text { Western Blot } \\
\text { SPR }\end{array}$ & 12 & 1 \\
\hline
\end{tabular}


Table 2: Summary of the High Data Density Investigations into PTEN's Interactome

\begin{tabular}{|c|c|c|c|c|c|c|c|}
\hline $\begin{array}{l}\text { Publication } \\
\text { Date }\end{array}$ & Authors (DOI) & Condition & $\begin{array}{l}\text { Isolation } \\
\text { Method }\end{array}$ & $\begin{array}{l}\text { Identification } \\
\text { Method }\end{array}$ & $\begin{array}{l}\text { Validation } \\
\text { Method }\end{array}$ & $\begin{array}{l}\text { No. of } \\
\text { Potential } \\
\text { Interactors }\end{array}$ & $\begin{array}{l}\text { No. of } \\
\text { Validated } \\
\text { Interactors }\end{array}$ \\
\hline 2011 & $\begin{array}{l}\text { Gunaratne et al. }{ }^{132} \\
\underline{(10.1074 / \text { ibc.M111.221184 })}\end{array}$ & $\mathrm{N} / \mathrm{A}$ & $\begin{array}{l}\text { PAP- } \\
\text { SILAC } \\
\text { TAP }\end{array}$ & LC-MS/MS & $\begin{array}{l}\text { Co-IP } \\
\text { Western Blot } \\
\text { Cell } \\
\text { Migration } \\
\text { Assay }\end{array}$ & 100 & 4 \\
\hline 2011 & $\begin{array}{l}\text { Maddika et al. }{ }^{133} \\
(\underline{\mathbf{1 0 . 1 0 3 8 / n c b 2 2 4 0}})\end{array}$ & $\mathrm{N} / \mathrm{A}$ & TAP & LC-MS/MS & Co-IP & 34 & 1 \\
\hline 2016 & $\begin{array}{l}\text { Verrastro et al. }{ }^{134} \\
\text { (10.1016/j.freeradbiomed.2015.11.004) }\end{array}$ & Oxidation & APD & LC-MS/MS & Western Blot & 97 & 4 \\
\hline
\end{tabular}




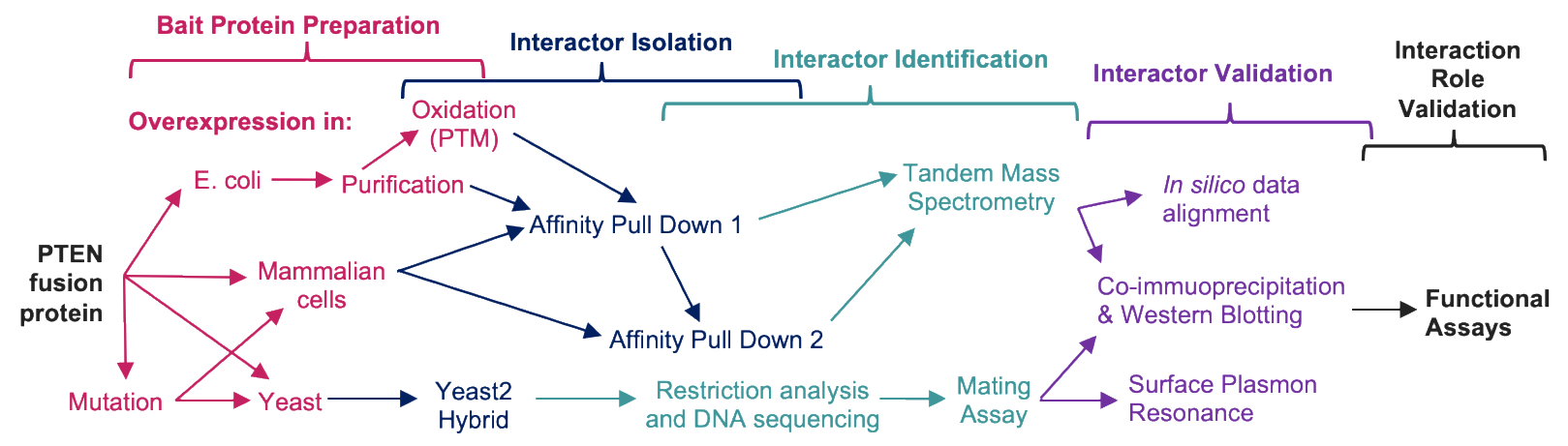

Figure 3. Pathways used in the 8 high data-content investigations into the interactome of PTEN. Once the PTEN fusion protein has been expressed in bait protein preparation and PTMs such as oxidation introduced if required (pink), protein-protein interactors can be isolated (dark blue) and identified (light blue). A small subset of these identified protein-protein interactors can be validated (purple) and for an even smaller subset a functional role may be proposed (black).

\subsection{High-Data Content Methods in the Search for Interactors of PTEN}

\subsection{Affinity Chromatography Assays and Tandem Mass Spectrometry}

Out of the 8 investigations into the interactome of PTEN, 6 utilised a tagged or fusion PTEN bait protein and affinity enrichment as the method of PPI isolation (Table 2). Table 3 shows the modified proteins and resins used by each investigation. There are several variations of affinity enrichment that have been used to identify the PTEN PPIs, including affinity pulldown, tandem affinity purification and parallel affinity purification, serving to address different limitations of these methodologies. Affinity pulldown assays use a tagged or fusion protein of interest as bait through immobilisation on a resin support such as sepharose or agarose. The immobilised bait is exposed to potential interactors (the prey proteins), either in vitro or through expression of the tagged/fusion bait in vivo. The resin is then washed to remove non-specifically bound protein, leaving the binding partners to be eluted along with the bait protein ${ }^{143}$. Binding partners are then 
usually identified using tandem mass spectrometry (LC-MS/MS), using quantitative methods, and resin-only controls are required to identify proteins that bind non-specifically to the resin ${ }^{23,144}$.

Tandem Affinity Purification (TAP) follows a similar process to affinity pull down (APD), except the protein of interest is double tagged and the affinity chromatography is performed sequentially, in tandem, using a two-step purification with a resin against each tag ${ }^{145}$. Parallel Affinity Purification (PAP), as with TAP, utilises a double-tagged protein and two resins. However, instead of a two-step purification, two one-step purifications are performed in parallel against each the different tags ${ }^{146}$. Many proteins interact as part of a complex and in some cases non-specific chromatographic techniques, such as ion-exchange and size-exclusion chromatography, have been used to separate these complexes from the initial elution mixture to further fractionate the sample and permit identification of separate complexes ${ }^{147-149}$. Stable Isotope Labelling of Amino Acids in Culture (SILAC) improves the specificity of interactor analysis; the cells must be cultured in media deficient of an essential amino acid and supplemented with normal or isotopically labelled forms of that amino acid to enable the abundance ratio of SILAC peptide pairs from tag only and tag+bait to be compared by mass spectrometry ${ }^{8,146,150}$. Interactors that show no change in abundance between the two samples can be assumed to be non-specific.

The general advantages and disadvantages of these different but related techniques have been extensively evaluated $^{8,10,13,145,146,151-155}$. All of the affinity chromatography-based techniques are economical and accessible. The whole protein can used as the bait, or regions of the protein can be expressed individually to identify specific domain binding partners. Notable disadvantages include masking of low abundance proteins, as well as false positive and negative results. Table 4 highlights the similarities and differences in the interactions identified between the different techniques. Both affinity pull down and parallel affinity purification can identify weaker and 
transient interactors but while tandem affinity purification reduces false positives due to the additional purification step, it also suffers from a higher rate of false negatives for the same reason. 
Table 3. Summary of High-Data Density Methods of Protein-Protein Interactor Isolation

\begin{tabular}{|c|c|c|c|c|c|c|}
\hline \multirow[t]{2}{*}{ Paper } & \multirow[t]{2}{*}{ Assay } & \multirow[t]{2}{*}{ Fusion Protein } & \multirow{2}{*}{$\begin{array}{l}\text { Tag size } \\
\text { (amino } \\
\text { acids) }\end{array}$} & \multirow{2}{*}{$\begin{array}{l}\text { Y2H } \\
\text { Conditions } \\
\text { Screen } \\
\text { System }\end{array}$} & \multicolumn{2}{|c|}{ Pull Down Conditions } \\
\hline & & & & & Resin & Expression Host \\
\hline $\begin{array}{l}\text { Gorbenko } \\
\text { et al. } 128\end{array}$ & $\mathrm{Y}_{2} \mathrm{H}^{\mathrm{A}}$ & $\begin{array}{l}\text { Wild type } \\
\text { C-terminal PTEN (aa201-403) } \\
\text { Phosphatase Dead PTEN (C124S) } \\
\text { Mutant PTEN (S370A) }\end{array}$ & $\mathrm{N} / \mathrm{A}$ & $\begin{array}{l}\text { Duplex- } \\
\mathrm{A}^{\mathrm{TM}}\end{array}$ & $\mathrm{N} / \mathrm{A}$ & $\mathrm{N} / \mathrm{A}$ \\
\hline $\begin{array}{l}\text { Crockett } \\
\text { et al. }{ }^{130}\end{array}$ & $\mathrm{APD}^{\mathrm{B}}$ & PTEN-His!U & 6 & $\mathrm{~N} / \mathrm{A}$ & Nickel-Agarose & $\begin{array}{l}\begin{array}{l}E . \quad c o l i \\
\text { specified) }\end{array} \\
\text { (not }\end{array}$ \\
\hline $\begin{array}{l}\text { Herlevsen } \\
\text { et al. } 131\end{array}$ & $\mathrm{APD}^{\mathrm{B}}$ & PTEN-HA ${ }^{@ \mathrm{C}}$ & 31 & $\mathrm{~N} / \mathrm{A}$ & $\begin{array}{l}\text { Anti-HA } \\
\text { Agarose }\end{array}$ & $\begin{array}{l}\text { Mammalian } \\
\text { (UMUC-3) }\end{array}$ \\
\hline $\begin{array}{l}\text { Ahn et al. } \\
135\end{array}$ & $\mathrm{APD}^{\mathrm{B}}$ & PTEN-HA ${ }^{@ U}$ & 31 & $\mathrm{~N} / \mathrm{A}$ & $\begin{array}{l}\text { Anti-PTEN } \\
\text { monoclonal } \\
\text { antibody- } \\
\text { conjugated } \\
\text { agarose }\end{array}$ & Murine (NIH 3T3) \\
\hline $\begin{array}{l}\text { Gorbenko, } \\
\text { et al. } 129\end{array}$ & $\mathrm{Y}_{2} \mathrm{H}^{\mathrm{A}}$ & C-terminal PTEN (aa201-403) & N/A & Duplex-A $^{\mathrm{TM}}$ & $\mathrm{N} / \mathrm{A}$ & N/A \\
\hline $\begin{array}{l}\text { Gunaratne } \\
\text { et al. }{ }^{132}\end{array}$ & $\begin{array}{l}\text { PAP }_{-} \\
\text {SILAC }^{\mathrm{D}} \\
\text { TAP }^{\mathrm{E}}\end{array}$ & $\begin{array}{l}\text { Wild type: PTEN-FLAP } \\
\text { Mutant: G20E PTEN-FLAP }\end{array}$ & 243 & $\mathrm{~N} / \mathrm{A}$ & $\begin{array}{l}\text { Anti- } \\
\text { FLAG/Anti- } \\
\text { GFP } \\
\text { Anti-GFP \& \& } \\
\text { Anti-S-protein }\end{array}$ & $\begin{array}{l}\text { Mammalian (LN299 } \\
\text { \& U87) }\end{array}$ \\
\hline $\begin{array}{l}\text { Maddika } \\
\text { et al. } 133\end{array}$ & $\mathrm{TAP}^{\mathrm{E}}$ & PTEN-SFB $^{\$ U}$ & 61 & $\mathrm{~N} / \mathrm{A}$ & $\begin{array}{l}\text { Streptavidin- } \\
\text { Sepharose \& } \\
\text { Anti-S-protein } \\
\text { Agarose }\end{array}$ & Mammalian: (293T) \\
\hline
\end{tabular}


Table 3. Summary of High-Data Density Methods of Protein-Protein Interactor Isolation

\begin{tabular}{|c|c|c|c|c|c|c|}
\hline \multirow[t]{2}{*}{ Paper } & \multirow[t]{2}{*}{ Assay } & \multirow[t]{2}{*}{ Fusion Protein } & \multirow{2}{*}{$\begin{array}{l}\text { Tag size } \\
\text { (amino } \\
\text { acids) }\end{array}$} & \multirow{2}{*}{$\begin{array}{l}\text { Y2H } \\
\text { Conditions } \\
\text { Screen } \\
\text { System }\end{array}$} & \multicolumn{2}{|c|}{ Pull Down Conditions } \\
\hline & & & & & Resin & Expression Host \\
\hline $\begin{array}{l}\text { Verrastro } \\
\text { et al. }{ }^{134}\end{array}$ & $\mathrm{APD}^{\mathrm{B}}$ & PTEN-GST $^{\% \mathrm{~N}}$ & 211 & $\mathrm{~N} / \mathrm{A}$ & $\begin{array}{l}\text { Glutathione } \\
\text { Agarose }\end{array}$ & E. coli $(\mathrm{DH} 5 \mathrm{a})$ \\
\hline \multicolumn{3}{|c|}{$\begin{array}{l}\text { Assays: } \\
\text { A: Yeast2Hybrid (Y2H) } \\
\text { B: Affinity Pull Down (APD) } \\
\text { C: Parallel affinity purification (PAP) } \\
\text { D: Stable Isotope Labelling of Amino Acids in Cell Culture } \\
\text { (SILAC) } \\
\text { E: Tandem Affinity Purification (TAP) }\end{array}$} & \multicolumn{4}{|c|}{$\begin{array}{l}\text { Tags: } \\
\text { !: Polyhistidine tag } \\
\text { @: Haemagglutinin (HA) tag } \\
\text { £: FLAG-Green Fluorescent Protein (GFP)-S-protein (FLAP) } \\
\text { tag } \\
\text { \$: S-protein-FLAG-Streptavidin-binding peptide (SFB) tag } \\
\text { \%: Glutathione-S-Transferase (GST) tag } \\
\text { C: C-terminal tag } \\
\text { N: N-terminal tag } \\
\text { U: Unknown tag location }\end{array}$} \\
\hline
\end{tabular}


Table 4. Advantages and Disadvantages of Affinity Chromatography Methods

\begin{tabular}{|c|c|c|c|c|c|c|}
\hline \multirow{2}{*}{ Method } & \multicolumn{4}{|c|}{ Identifies: } & \multirow{2}{*}{$\begin{array}{c}\text { False positives } \\
\text { (resin bias) }\end{array}$} & \multirow{2}{*}{$\begin{array}{c}\text { False negatives } \\
(>1 \text { step } \\
\text { purification) }\end{array}$} \\
\hline & $\begin{array}{l}\text { Direct } \\
\text { interactors }\end{array}$ & $\begin{array}{l}\text { Indirect } \\
\text { interactors }\end{array}$ & $\begin{array}{l}\text { Weak } \\
\text { interactors }\end{array}$ & $\begin{array}{l}\text { Transient } \\
\text { interactors }\end{array}$ & & \\
\hline Affinity Pull Down & $\checkmark$ & $\checkmark$ & $\checkmark$ & $\checkmark$ & $\checkmark$ & $\downarrow$ \\
\hline $\begin{array}{l}\text { Tandem Affinity } \\
\text { Purification }\end{array}$ & $\checkmark$ & $\checkmark$ & $\downarrow$ & $\downarrow$ & $\downarrow$ & $\uparrow$ \\
\hline $\begin{array}{l}\text { Parallel Affinity } \\
\text { Purification }\end{array}$ & $\checkmark$ & $\checkmark$ & $\checkmark$ & $\checkmark$ & $\downarrow$ & $\downarrow$ \\
\hline
\end{tabular}


Advantages and disadvantages of affinity tags for isolation of proteins and investigation of PPIs have been evaluated previously, from expression and purification conditions to effect on protein properties ${ }^{156}$. A variety of tags have been used for PTEN (Table 3), all of which are suitable for mild purification strategies.

One of the major considerations of the effect of a tag on the protein of interest is correct folding and availability of protein interaction sites. This risk increases with the size and different properties of the tag (Table 3). Whilst the polyhistidine tag, used by Crockett et al. ${ }^{130}$ is small and as such less likely to have a negative effect on protein folding or interaction due to size, it suffers from limited specificity, especially over basic proteins, and it can chelate divalent cations. This renders a polyhistidine tag unsuitable for any enzymes requiring divalent cation co-factors, for example magnesium $\left(\mathrm{Mg}^{2+}\right)$, for activity. Whilst initial studies reported $\mathrm{Mg}^{2+}$ as a co-factor for PTEN, on elucidation of its crystal structure $\mathrm{Mg}^{2+}$ was not found as part of the PTEN crystal and PTEN was found to be active in $\mathrm{Mg}^{2+}$-free buffers ${ }^{28,157}$, suggesting that it is not a requirement. Divalent cation chelation also occurs with commonly used buffer additives, such as EDTA, and can affect protein-protein interactions that are dependent on calcium $\left(\mathrm{Ca}^{2+}\right)$ or zinc $\left(\mathrm{Zn}^{2+}\right)$ cations ${ }^{13}$, so care is required in the design of buffer composition.

The GST tag is 243 amino acids in length and was used by Gunaratne et al. and Verrastro et al. 132, 134, whereas Maddika et al. ${ }^{133}$ used the 211 amino acid FLAP (FLAG-GFP-S protein) tag. Larger tags have an increased risk of affecting protein properties, such as correct folding, conformation and PPIs. This risk is increased further still with the GST tag due to the potential dimerization of GST ${ }^{156}$. Evaluation of PTEN's catalytic activity with and without GST showed that there was no significant different between the tagged and untagged protein with regards to phosphatase activity towards $p$-nitrophenyl phosphate (PNPP) ${ }^{158}$, although this is not the most 
sensitive or specific assay for PTEN's phosphatase activity. The phosphatase activity of PTENGST was confirmed by another study evaluated here using 3-O-methylfluorescein 6-phosphate (OMFP) as a substrate ${ }^{134}$. PTEN has higher affinity for $\mathrm{PIP}_{3}\left(\mathrm{~K}_{\mathrm{m}} 30 \mu \mathrm{M}\right)$ in comparison to the artificial substrates OMFP $\left(\mathrm{K}_{\mathrm{m}} 216 \mu \mathrm{M}\right)$ and $\mathrm{pNPP}\left(\mathrm{K}_{\mathrm{m}} 25,600 \mu \mathrm{M}\right){ }^{159}$. PIP 3 has a molecular weight of $644.2 \mathrm{~g} / \mathrm{mol}$, whilst OMFP and pNPP have molecular weights of $426.3 \mathrm{~g} / \mathrm{mol}$ and 217.1 $\mathrm{g} / \mathrm{mol}$, respectively; this decreasing size may result in decreased interference with the tag. However, the conservation of phosphatase activity indicates that protein folding is correct for the substrate binding domains and active site formation.

The location of the tag also needs to be considered, as it may elicit different effects depending on the terminus it is located on. For example, at the catalytic N-terminal domain of PTEN there is a $\mathrm{PIP}_{2}$ binding domain (amino acids 1-13), whilst the membrane binding $\mathrm{C}$-terminal domain contains the PDZ binding motif (amino acids 401-403). This indicates that a tag on the $\mathrm{N}$-terminus may affect binding to $\mathrm{PIP}_{2}$ and phosphatase activity, whilst a tag on the C-terminus could affect protein-protein interactions through the PDZ domain and membrane binding. While this has not yet been done for PTEN, one approach to determining impact of the tag on identified PPIs would to trial the tag on both the $\mathrm{N}$ and $\mathrm{C}$ terminus ${ }^{160}$.

The papers reviewed here used two main strategies for PPI isolation. The first involves expression of a PTEN-fusion protein using Escherichia coli (E. coli) before lysis, purification and subsequent affinity pull down ${ }^{130,134}$. The second is the expression of the PTEN-fusion protein in mammalian cells, before subsequent lysis and affinity pulldown, negating the requirement of a pre-purification step ${ }^{131-133,135}$. An advantage of the E. coli approach is that the specific phosphatase activity of the PTEN fusion protein can be assessed before affinity pull down. An 
additional advantage to this approach in general is that a wide range of proteins can be overexpressed in bacteria at a relatively low cost. In contrast, expressing a PTEN fusion protein in mammalian cells ensures the presence of the appropriate machinery to allow correct folding and PTM of the expressed fusion protein. Protein folding and post-translational modification are a key considerations in the use of an overexpressed protein to search for PPIs, as they are important for protein interactions 161,162 and as such, key in the identification of physiologically relevant interactors. If a protein is not folded correctly, then regions of proteins that are normally available for PPIs could be hidden and vice versa. Stretches of amino acids, for example hydrophobic regions, that are normally confined to the inner portion of the protein could be exposed leading to an increase in non-specific binding and false positive identification of interactors as well as false negatives. It is worth noting that E. coli expressed fusion proteins of Homo sapiens PTEN were used in the identification of PTEN's crystal structure as well as catalytic activity, indicating that the lack of mammalian expression machinery with regards to the production of catalytically active, correctly folded PTEN is not prohibitive ${ }^{28}$. There are other advantages to pulling down the PTENprotein interactor complexes directly from a cellular environment, as described by several groups 131-133, 135, and discussed further in section 3.4.

Once the protein interactors have been isolated by elution of the PTEN-protein complexes from the resin support, identification and quantification of the PPIs can be performed through the use of standard proteomics approaches, including SDS-PAGE and LC-MS/MS. Quantification can be performed by label-free approaches, or isotope labelling methods such as SILAC. In the comparison of a control experiment using unmodified resin (or resin modified with an appropriate control, e.g. an alternative antibody), proteins with very similar abundances can be assumed to be 
non-specific interactors, whereas proteins with increased abundance are likely to be specific interactors. LC-MS/MS sequencing of peptides produced by tryptic digestion (or other proteases) is now the most commonly used approach to identification of proteins in complex mixtures, and consequently it also plays a leading role in the identification of PPIs. The advantages and limitations in the use of LC-MS/MS, particularly in the context of affinity purification, have been extensively reviewed ${ }^{13,163-165}$.

\subsection{Yeast 2-Hybrid Assay and DNA Sequencing}

The basis of the yeast 2-hybrid $(\mathrm{Y} 2 \mathrm{H})$ technique relies on a transcription factor with two functional domains that can be separately expressed as fusion proteins with the protein of interest (bait) and potential interacting proteins (prey) ${ }^{166}$. A common example is use of the Gal4 transcription factor to generate two fusion proteins: a DNA-binding domain Gal4BD+Bait and an activator domain Gal4AD+Prey, which following interaction leads to the transcription of LacZ as a reporter gene, although a variety of different transcription factors and reporting systems can be used 19,167 . If the bait and the prey are interacting proteins, the two domains of the transcription factor will be in close proximity, activating gene expression of reporter genes ${ }^{166}$. This allows detection of PPIs through permitted growth on restrictive selection media or an observable colour change ${ }^{18,166}$. As with the affinity purification strategies discussed above, the $\mathrm{Y} 2 \mathrm{H}$ assay has advantages and limitations. Firstly, the $\mathrm{Y} 2 \mathrm{H}$ relies on the orientation of the interaction between the bait and prey proteins being appropriate to allow the two domains of the transcription factor to achieve a functional interaction ${ }^{168}$. Moreover, whilst $\mathrm{Y} 2 \mathrm{H}$ can identify interacting proteins, structural information on this interaction is not produced ${ }^{168}$. One limitation of particular relevance to PTEN, and investigations into cytoplasmic proteins with a role in signal transduction in general, 
is that the interactions need to be able to take place within the yeast's nucleus for gene transcription to occur ${ }^{13,166}$. Other limitations have been cited, as PPIs involving the N-terminal domain of the bait protein are blocked, but this can be overcome using a Y2H system with reversed polarity ${ }^{13}$.

The two papers evaluated here that utilised the Y2H system to search for PTEN PPIs originated from the same research group ${ }^{128,129}$. Both studies used the Duplex- $\mathrm{A}^{\mathrm{TM}} \mathrm{Y} 2 \mathrm{H}$-system and LexA fused bait proteins. The original paper used 4 constructs, whilst the following paper used only the C-terminal domain of PTEN ${ }^{128,129}$. In both instances, the PTEN bait proteins were screened by transfected cDNA libraries from Mouse Embryo, HeLa and Colon Cancer cells ${ }^{128,}{ }^{129}$. Clones identified as positive were subjected to further analysis using a mating assay and identification of the parent cDNA using DNA sequencing. For the full length PTEN, 43 (86\%) of the 50 primary positive clone identified from the three libraries (colon cancer, mouse embryo and HeLa) were confirmed by the mating assay ${ }^{128}$, although this is decreased to 36 strongly associating clones (72\%) when taking account the 7 clones that showed weak attraction, whereas in the assay using the $\mathrm{C}$-terminal region only 27 (13\%) of the primary positive clones were confirmed as positive by the mating assay ${ }^{129}$.

\subsection{Affinity Chromatography vs Yeast2Hybrid: A comparison}

A comparison of the affinity chromatography and $\mathrm{Y} 2 \mathrm{H}$ approaches to uncovering PPIs has been made in numerous reviews ${ }^{10,13,154}$, and it is apparent that the nature of the protein and interactions of interest determine which approach is most appropriate. Identification by $\mathrm{Y} 2 \mathrm{H}$ is suited to investigations into binary reactions of single, direct protein interactors, whereas affinity purification chromatography has the advantage of being able to isolate protein complexes. Affinity chromatography approaches also work well for proteins participating in signal transduction, where 
it might be expected that many protein interactions are transient in nature and often as part of a complex. As mentioned above, there are benefits and limitations to affinity pull down, tandem affinity chromatography and parallel affinity chromatography (Table 4). Notably, with regards to affinity enrichment methods, it is not possible from the initial data to separate primary and secondary interactors, highlighting the importance of validation.

It is widely accepted that PTEN is recruited to a complex of proteins, giving further weight to the benefits of affinity enrichment for its investigation ${ }^{6,169}$. The benefits of using mammalian or E. coli approaches to affinity chromatography have been discussed above although this is influenced by the precise aims of each study. Verrastro et al. sought to identify how the PTEN interactome changes under oxidative stress through treatments with hydrogen peroxide ${ }^{134}$. The PTEN-GST was purified from E. coli and either reduced or oxidised before analysis of phosphatase activity, aggregation and binding partners ${ }^{134}$. In this regard, the use of affinity chromatography is more suited than $\mathrm{Y} 2 \mathrm{H}$, and the in vitro approach allows the effect of oxidation of the protein itself to be characterized, before the identification of binding partners. While in this study the binding partners identified were from lysates of mammalian cells in normal growth medium, an additional advantage identified in the paper is that lysates from cells subjected to oxidative stress, or indeed other stress conditions, could be used to identify changes in PPIs due to the alterations in the total proteome (e.g. PTMs of interacting proteins) because of the stress condition ${ }^{134}$.

\subsection{Cellular and Physiological Context}

As introduced above, the cell type and physiological status of the cell is likely to have significant impact on PPIs ${ }^{131-133,135}$, as many may occur only during certain cellular events or require specific post-translational modifications. For example, in vivo PTEN is phosphorylated by CK2, which 
results in inactivation and affects PTEN's recruitment to a complex at the membrane, as discussed in section $2.4^{6}$. The dynamic nature of PPIs is illustrated by the changes in the interactome of the scaffold protein $14-3-3 \beta$ on activation of the insulin-PI3K-AKT pathway ${ }^{170,171}$, and the main interactions between proteins in complexes are non-covalent bonds, which are heavily influenced by the environment in which they are formed ${ }^{13}$. Evaluation of the composition of protein complexes with PTEN by direct IP from mammalian cells should therefore yield data that are more physiologically relevant ${ }^{13}$, although it has also been suggested that the use of genetically modified cell lines in high-data content interactome studies may compromise this ${ }^{171}$, and it can be difficult to identify the changes to the interacting proteins responsible for the changes in interactome. For all methods, introduction of mutations to the bait, as discussed in section 4.3 , or changes to the status of the host cell are also likely to make significant differences.

The (patho)-physiological context may be significantly affected by the cell line being studied, for example whether it is a cancerous or non-cancerous cell line ${ }^{172}$ and whether the PTEN is expressed from a plasmid or native genome, as PTEN and other signalling proteins are commonly mutated in cancer cells and signalling pathways may be significantly dysregulated. Seven of the eight papers reviewed here used either mammalian embryonic or cancerous cell lines of various tissue origins for the IP or prey protein source, while only 1 used a non-cancerous cell type (Table 5). Embryonic and cancer cells have many similarities, such as high proliferation rates and a dependence on glycolytic metabolism ${ }^{173}$, and therefore might be expected to show some similarities in PTEN AKT signalling status. Interestingly, while most of the cell lines used in the papers reviewed here expressed wild type PTEN, one cell line had a homozygous deletion of PTEN (UMUC-3) and one cell line had a splice mutation (U87) ${ }^{131,132,174}$. While there were differences reported in interactions from these studies, the relatively small number of PTEN interactome 
studies that have been reported means that it is not possible to draw significant conclusions on interactome differences. Nevertheless, it is likely that they do exist, as a quantitative comparison of the proteome networks of HCT-116, a colon cancer cell line, and 293T, a human embryonic kidney cell line, showed that $54 \%$ of the expressed proteome differed between the two cell lines 175 , indicating that the protein environment experienced by the bait would be substantially different. The context dependence of PTEN interactors is explored more explicitly in sections 4.3 and 4.4 for mutation and oxidation dependent interactors ${ }^{132-134}$.

Table 5. Summary of the Cell Lines used as the Prey Protein Source for Affinity Chromatography

\begin{tabular}{|l|l|l|l|}
\hline \multirow{2}{*}{ Paper } & \multicolumn{2}{l|}{ Prey Source } & \multicolumn{2}{l|}{ PTEN Expression } \\
\cline { 2 - 4 } & Cell Line & Cell Type & Wild type $^{174}$ \\
\hline $\begin{array}{l}\text { Crockett et al. (2005) } \\
\mathbf{1 3 0}\end{array}$ & $\begin{array}{l}\text { Mammalian } \\
\text { (SUDHL-1) }\end{array}$ & Cancer (lymphoma) \\
\hline $\begin{array}{l}\text { Herlevsen et al. (2007) } \\
\mathbf{1 3 1}\end{array}$ & $\begin{array}{l}\text { Mammalian } \\
\text { (UMUC-3) }\end{array}$ & Cancer (bladder) & $\begin{array}{l}\text { Homozygous deletion (-/- } \\
)^{174}\end{array}$ \\
\hline $\begin{array}{l}\text { Ahn et al. (2008) 135 } \\
\text { Gunaratne al. } \\
\text { (2011) 132 }\end{array}$ & $\begin{array}{l}\text { Murine } \\
\text { (NIH 3T3) } \\
\text { (LN299 \& } \\
\text { U87) }\end{array}$ & Fibroblast & Wild Type \\
\hline $\begin{array}{l}\text { Maddika et al. (2011) } \\
\mathbf{1 3 3}\end{array}$ & $\begin{array}{l}\text { Mammalian: } \\
(293 T)\end{array}$ & Embryonic (kidney) & Wild Type \\
\hline $\begin{array}{l}\text { Verrasto et al. (2016) } \\
\mathbf{1 3 4}\end{array}$ & $\begin{array}{l}\text { Mammalian } \\
\text { (HCT-116) }\end{array}$ & Cancer (colon) & Wild type ${ }^{174}$ \\
\hline
\end{tabular}

\subsection{Validated PTEN Interactors}

As mentioned previously, both the $\mathrm{Y} 2 \mathrm{H}$ and affinity chromatography approaches to investigating PPIs have an inherent risk of false positive identifications. This risk can be mitigated in part 
through the use of validation methods to verify that an interaction has taken place, and it is recommended to use more than one method to confirm potential interacting proteins. The most common approach to validation is to confirm the interaction of the two proteins by coimmunoprecipitation confirmed by western blotting, although surface plasmon resonance (SPR) has also been used ${ }^{18}$. Co-immunoprecipitation was utilised by all studies except for the original Y2H investigation by Gorbenko et al. and Crockett et al. ${ }^{128,130}$. Alternatively, the interaction can be confirmed in situ, for example verifying co-localization within the cell using techniques such as fluorescence resonance energy transfer (FRET) and bioluminescence resonance energy transfer (BRET) ${ }^{18}$. A third approach is to compare in vitro and in silico data, as used by Gorbenko et al. ${ }^{128}$. Due to the large number of potential protein interactors frequently identified by either affinity chromatography techniques or $\mathrm{Y} 2 \mathrm{H}$, typically only a small number of interactions are actually be validated, and of these a functional role can only be elucidated for a smaller subset still. Figure 4 illustrates the validated PTEN interactors found though high-data content methods and whether a functional role of the interaction has been found. Figure 4 highlights the large number of potential interactors identified through high data-content methods and how this decreases substantially in terms of validated interactors from these studies, decreasing again for those where a functional role of the interaction was proposed. Out of 15 total validated interactors, 11 were PTEN interactors identified previously using more classical biochemical techniques and insights. The high proportion of known interactors identified across these 8 studies provides evidence for the validity of both the $\mathrm{Y} 2 \mathrm{H}$ and affinity chromatography methods of PPI identification, but the number of new validated interactors is small. Validated novel interactions included AEBP1, TFG, IQGAP and DDB1 128, 131, 132, 134 . In order to characterise further the interaction with a specific binding region of PTEN, 2 out of the 8 papers compared interactions of isolated domains of PTEN 
with the protein of interest (Figure 4) ${ }^{128,133}$; identification of where the interactor binds could help to elucidate a function for the interaction. It has been reported that the effect of PPIs on PTEN's phosphatase activity depends on the site of binding; phosphatase activity is enhanced through PPIs with the PDZ motif, whereas a reduction is seen for PPIs with the $\mathrm{C} 2$ or phosphatase domain ${ }^{176}$, ${ }^{177}$. Functional validation for three interactors, NUDTL16L1, NEDD4-1 and WWP2, was achieved 132, 133, and is discussed further in sections 4.1 and 4.2. The interactions of CALU and WWP2 with PTEN were found to be impacted by PTEN mutation, the interaction of Trx-1, Prdx-1 and Anxa1 were found to be oxidation-dependent. These context-dependent interactors are discussed in section 4.3 and 4.4 .

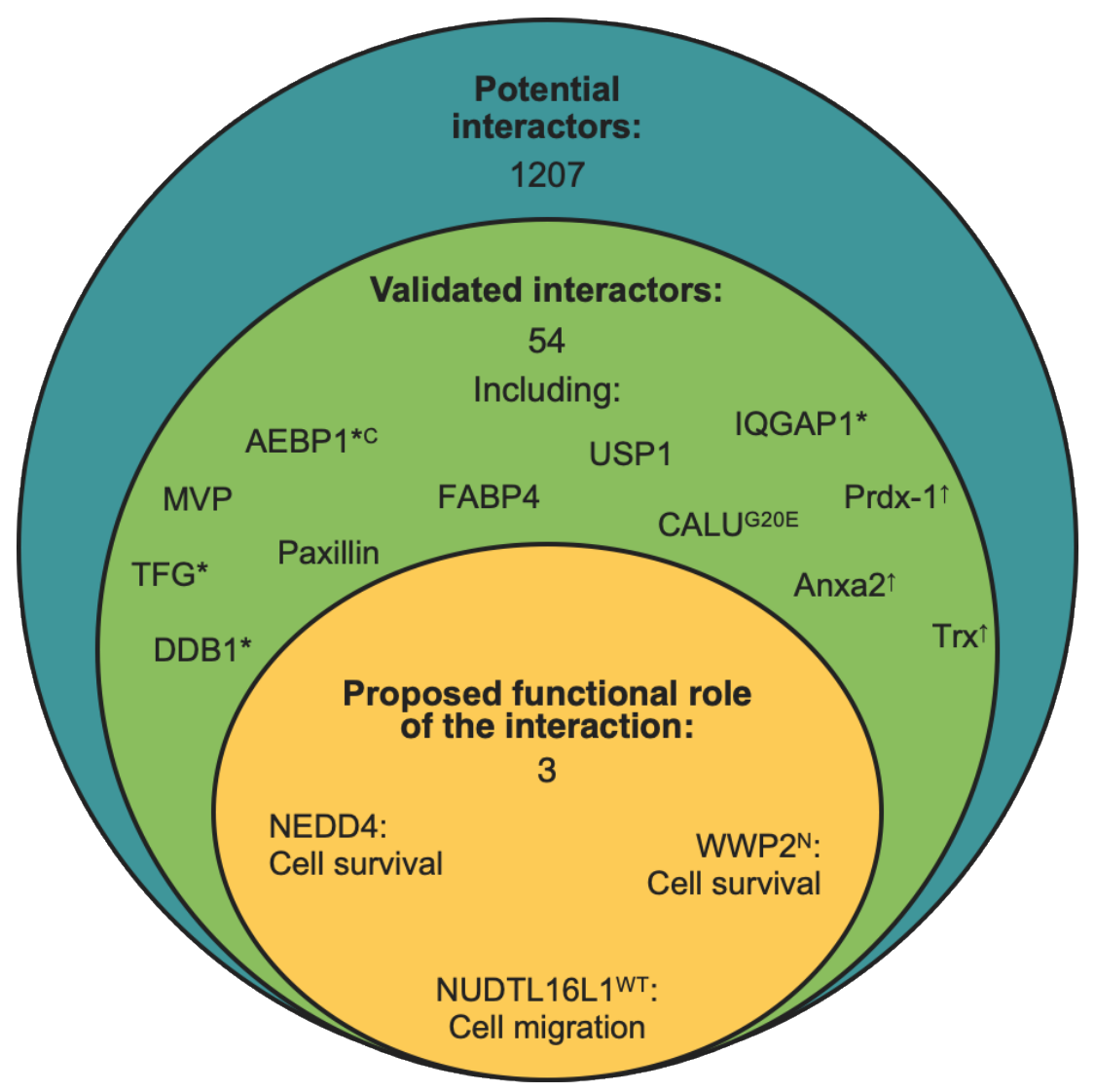

Figure 4. The number of potential PTEN interactors, validated PTEN interactors and interactors with a proposed functional role for the interaction with PTEN. Key: *: a novel PTEN interactor; 
$\uparrow$ : an interactor with increased binding to oxidised PTEN; C: an interactor shown to bind to PTEN's C-terminal domain; N: an interactor shown to bind to PTEN's N-terminal domain; G20E: an interactor specific for the G20E PTEN mutant; WT: an interactor specific for wild-type PTEN, not the G20E mutant.

\subsection{NUDTL16L1}

NUDTL16L1 was identified as having a regulatory role in cell migration through transwell migration assays with cells transfected with either the wild-type or G20E mutant with siRNA against NUDT16L1 or scrambled siRNA ${ }^{132}$. Wild-type cells showed suppressed migration compared to the control, whilst the G20E mutant showed an increase ${ }^{132}$. Cells where NUDT16L1 expression was knocked down using siRNA showed an increase in cell migration compared to the control ${ }^{132}$. When measuring AKT phosphorylation to identify whether this was dependent on activation of the AKT pathway, no difference in levels of phosphorylation was found ${ }^{132}$. It was therefore proposed that regulation of migration by the PTEN-NUDTL16L1 interaction is independent of lipid phosphatase activity ${ }^{132}$. The loss of the PTEN-NUDTL16L1 interaction in the cancer-associated G20E mutant allowed an increase in cell migration ${ }^{132}$.

\subsection{Ubiquitin ligases: WWP2 and NEDD4-1}

WWP2 and NEDD4-1 are HECT-domain-containing E3 ubiquitin ligases with a regulatory role in protein degradation by the $26 \mathrm{~S}$ proteasome via ubiquitin dependent pathways ${ }^{133,}{ }^{178}$. The mechanism of action of HECT-family ligases involves transfer of ubiquitin to a substrate lysine residue after donation of ubiquitin from E2 enzymes ${ }^{178}$. The effect of ubiquitination on PTEN is discussed in section 2.4. NEDD4-1 was initially identified as a ubiquitin ligase for PTEN in 2007 
92, 107. Previous investigations into PTEN nuclear import indicated that mono-ubiquitinylation of PTEN is required and can impart a protective mechanism to preserve the tumour suppressive role of PTEN by avoiding PTEN degradation ${ }^{92}$. A further identification of an interaction between PTEN and NEDD4-1 was achieved in a high-data content study ${ }^{135}$, and fluorescence microscopy monitoring of DAPI-staining after transfection with PTEN and/or NEDD4-1 showed that apoptosis was inhibited when NEDD4-1 was co-transfected with PTEN. Immunoblotting showed a reduction in endogenous PTEN on transfection of cells with NEDD4-1, thought to be due to degradation via the UPS system, confirming previous studies reporting NEDD4-1 as a ubiquitin ligase for PTEN 92, 107. Conversely, cells transfected with PTEN showed a reduction in endogenous NEDD4-1, and mutation of the catalytic cysteine $(\mathrm{C} 124 \mathrm{~S})$ of PTEN resulted in loss of down-regulation of NEDD4-and identified that the downregulation of NEDD4-1 is caspase-independent through the PI3K/AKT pathway ${ }^{135}$.

The interaction of PTEN and WWP2 was confirmed through co-immunoprecipitation, deletion of either the $\mathrm{N}$ - or C-terminal domains of PTEN and repeat co-immunoprecipitation experiments showed that the binding site for WWP2 is the phosphatase domain, more specifically within amino acids 100-187 ${ }^{133}$. The use of ubiquitination assays showed polyubiquitination of PTEN in HeLa cells transfected with wild-type WWP2, but not with a C838A mutant of WWP2 where catalytic activity is abolished ${ }^{133}$. The ubiquitination of PTEN by WWP2 was further demonstrated through in vitro assays with PTEN-GST, wild type or mutant WWP2 and an E2 ubiquitin-conjugating enzyme ${ }^{133}$, and on siRNA silencing of WWP2 expression ubiquitination of PTEN was decreased 133. Functionally, the reduction in the levels of PTEN and increase in cellular proliferation on the depletion of WWP2 indicated the PTEN-dependent oncogenic potential of WWP2 ${ }^{133}$. Comparison with the silencing of two further E3 ligases, EDD1 and NEDD4-1, showed that the levels of PTEN 
ubiquitination remained unaffected ${ }^{133}$. For this reason, WWP2 was proposed as the lead E3 ligase for PTEN, confirming PTEN as a WWP2 substrate ${ }^{133}$. Recently WWP2 has been shown to be a physiological ubiquitin ligase in mice, acting to promote PTEN degradation in vivo ${ }^{179}$.

Since the identification of NEDD4-1 as a PTEN ligase, there have been conflicting reports suggesting that both PTEN stability and ubiquitinylation were unaffected in cells deficient in NEDD4-1 ${ }^{180}$. This discrepancy was postulated to be due to the use of overexpression of NEDD41 in the earlier papers, whereas in later papers physiological levels of NEDD4-1 were used ${ }^{180}$. Maddika et al also used physiological levels of the E3 ligases NEDD4-1 and WWP2, confirming the WWP2-PTEN interaction but not the NEDD4-1-PTEN interaction ${ }^{133}$. This provided further evidence that initial over-expression of NEDD4-1 could have caused an exaggerated relationship 133, 180. Direct comparisons of the ubiquitinylation of NEDD4-1 and WWP2 shows that whilst both

targeted lysine residues for ubiquitin transfer, WWP2 was more active ${ }^{181}$. At the time of writing, BioGrid ${ }^{113}$ includes 14 identifications of NEDD4-1-PTEN and 13 identifications of WWP2-PTEN interactions. WPP2 was not found to have a role in the nuclear import of PTEN, highlighting the multifaceted effect of ubiquitinylation of PTEN within the cell and the divergence of the roles of different E3 ligases ${ }^{133}$.

\subsection{Mutation Dependent Interactors: CALU and WWP2}

PTEN is commonly found to be mutated in cancer ${ }^{2}$, and as highlighted in section 3.4 , mutations and cellular context, especially those that alter or mimic post-translational modifications, may significantly alter PPIs. Mutations, specifically in the context of endometrial cancer, have been mapped to PTEN and their effect on the 3D structure suggested ${ }^{182}$. It was proposed that PTEN mutations altering the size and properties of the amino acid side could cause changes to the 
physical interactions of PTEN ${ }^{182}$; for example, active site mutations (H123Y, R130G, R130Q and R130L) reduce the local environments electrostatic potential, altering specificity of interaction with $\mathrm{PIP}_{3}{ }^{182}$.

Whilst the majority of the high-data content studies searched for wild-type PTEN interactions, the main focus for Gunaratne et al. was to identify whether the interactome of the cancer-associated PTEN mutant G20E was different to wild-type PTEN ${ }^{132}$. Comparison of the wild-type interactome with that of the G20E mutant showed that whilst 2 out of 4 validated interactors were non-specific, only one, CALU, specifically bound G20E PTEN ${ }^{132}$. The G20E specific interactor CALU is a calcium-binding protein involved in the protein sorting and folding functions of the endoplasmic reticulum functions ${ }^{183}$.

Although a comparison of wild-type to mutant PTEN was not the main focus for Maddika et al. ${ }^{133}$, during validation they sought to identify whether a Y155 mutant of PTEN also interacted with WWP2, as the stability of PTEN has been reported to be affected by tyrosine mutation. Ubiquitinylation by WWP2 of a patient-derived PTEN tyrosine mutant (Y155F) located within the proposed WWP2 binding domain (a.a. 100-182) was analysed, and the Y155F mutant showed increased WWP2 binding, enhanced polyubiquitinylation and a reduced amount of PTEN ${ }^{133}$. These findings led to the proposal that an unknown tyrosine kinase could have a regulatory role in the interactions of WWP2 and PTEN ${ }^{133}$.

\subsection{Oxidation Dependent Interactors: Trx-1, Prdx-1 and Anxa2}

Oxidation of PTEN is widely reported to cause inactivation and altered interactions as discussed in section 2.4. A recent review has evaluated redox regulation of PTEN and the roles of thioredoxin and peroxiredoxin ${ }^{184}$. Previous low-data content investigations into the interactions of thioredoxin 
(Trx) and DJ-1 with PTEN identified increased binding on oxidation ${ }^{118,185}$. Verrastro et al sought to build upon this with a high-data content comparison of the PPIs with oxidised and untreated PTEN ${ }^{134}$. Out of the 3 proteins validated to have increased binding with oxidised PTEN, 2 were the redox proteins thioredoxin-1 (Trx-1) and peroxiredoxin-1 (Prdx-1), previously shown to interact with PTEN. Prdx-1 protects cells from $\mathrm{H}_{2} \mathrm{O}_{2}$-induced oxidative damage ${ }^{186}$. A previous study reported conflicting data, as decreased binding of Prdx-1 to PTEN was identified during conditions of oxidative stress ${ }^{123}$. This decrease in binding was thought to be due to oxidation of Prdx-1 at C51, and as such is fundamentally different conditions to those used by Verrastro et al., where only the PTEN was oxidised ${ }^{123,134}$. This could be seen as a limitation of the high-data content search for redox interactors, where only the bait was oxidised, as noted by the authors and described in section 3.1. Verrastro et al. justified the use of this approach as a strength of the investigation, in that this allows a targeted investigation into how the formation of the disulfide bond, a regulatory mechanism in the activity of PTEN, affects PPIs ${ }^{134}$. Further experimentation with oxidised cell lysates, for example, would allow expansion into how oxidation of prey proteins effects PPIs with PTEN. This multi-layered approach is advantageous in providing detail on how oxidation effects PPIs from both the prey and bait perspectives, that broader approaches, such as oxidation of whole lysates and subsequent pull-down of PTEN complexes, wouldn't give. Trx-1 is known to be a physiological reductant of PTEN ${ }^{7}$, and an increase in Trx-1 binding to oxidised PTEN was reported to involve Trx-1-PTEN interaction through a C2 domain disulfide bond, inhibiting catalytic activity and increasing tumorigenesis ${ }^{118}$. The third protein identified to have increased binding to oxPTEN was Anxa2, a calcium-dependent phospholipid binding protein ${ }^{134}$. Anxa2 has a diverse role in cellular processes from membrane trafficking to signal transduction and apoptosis ${ }^{132,} 187$. Elevated Anxa2 protein levels are induced by $\mathrm{H}_{2} \mathrm{O}_{2}$, depletion of which 
identified it as a redox regulatory protein with a role in tumorigenesis ${ }^{187}$. Recently, Anxa2 has been shown to interact with PTEN through its C8 residue, upregulating PTEN's negative regulation of the PI3K and inhibiting the Akt pathway ${ }^{188}$.

\subsection{Summary and perspectives}

It can be seen that both the $\mathrm{Y} 2 \mathrm{H}$ and affinity chromatography approaches into investigating the interactome of PTEN have been important in the identification and confirmation of a large number of PTEN interactors, although validation by more targeted and specific approaches is needed to increase confidence and demonstrate functional relevance. Using these methods, a G20E mutantspecific interaction has been validated, as well as 3 redox specific interactions. These and other differential interactions may be important in pathophysiological scenarios such as dysregulation of cell proliferation and apoptosis in cancer, or metabolic dysregulation in diabetes and obesity. This emphasises the importance of uncovering the network of PTEN interactors, providing data to corroborate previous studies whilst also generating new information and lines of enquiry. Whilst the interactome of wild-type PTEN has been investigated using various cell lines and fusion tags by different groups, producing data that can be aligned to further increase confidence in the protein hits, the effect of mutations and post-translational modifications on PTEN's interactome is much less well established and represents a significant knowledge gap in the field. In addition, as discussed in section 3.4 the cell type and status, or mutation to the bait, are likely to have significant impact on the interactome, and this is an important and interesting area of study. However, the majority of the small number of studies reported so far have been undertaken with rapidly proliferating cell types under a limited set of conditions, often with overexpression of the bait, so drawing any overall conclusions on the differences between cell types is difficult, and more studies 
with different cell types under different growth and stimulation conditions are needed to fully understand the role of the PTEN interactome. Using high data-content approaches and applying them to other mutations and modifications would allow insights into changes to the PTEN interactome that may be brought about by other pathophysiologically important states.

\section{ASSOCIATED CONTENT}

Supplementary table 1. Published interactions with PTEN (.xls) lists the 755 published interactions with PTEN curated by BioGRID ${ }^{113}$. For each interaction, the role of the interactor (bait or hit) as well as the organism and experimental evidence is described. The dataset in which the interaction was published is also listed.

Supplementary table 2. Gene Ontology Biological Processes associated with PTEN (.xls) lists the 64 biological processes associated with PTEN, curated by BioGRID ${ }^{113}$. The gene ontology (GO) biological processes listed here refers to both the larger biological processes in which PTEN participates, as well as more specific cellular processes.

Supplementary table 3. Published interactions with PTEN (.xls) lists the 227 published interactions with PTEN curated by IntAct ${ }^{114}$. For each interaction, the role of the interactor (bait or hit) is listed as well as the experimental evidence and the dataset in which the interaction was published.

\section{AUTHOR INFORMATION}

\section{Corresponding Author}


*Corinne Spickett, School of Life and Health Sciences, Aston University, Aston Triangle, Birmingham, B4 7ET, UK. Tel.+44 (0)121 204 3005. Email: c.m.spickett@aston.ac.uk

\section{Author Contributions}

The manuscript was written through contributions of all authors. All authors have given approval to the final version of the manuscript.

\section{Funding Sources}

This project has received funding from Aston University (UK) and the European Union's Horizon 2020 research and innovation programme under the Marie Sklowdowska-Curie grant agreement number 675132 www.masstrplan.org.

\section{ABBREVIATIONS}

AKT, protein kinase B; BRET, bioluminescence resonance energy transfer; CALU, calumenin; CK2, casein kinase 2; DNA, deoxyribonucleic acid; DTT, dithiothreitol; DUP, dual-specificity phosphatase; E. coli, Escherichia coli; EDTA, ethylenediaminetetraacetic acid; FLAP tag, FLAGgreen fluorescent protein-S protein tag; FOXO, forkhead box O; FRET, fluorescence resonance energy transfer; GO, gene ontology; Grdx, glutaredoxin; GSH, glutathione; GSK3, glycogen synthase kinase 3; GST, glutathione-S-transferase; $\mathrm{H}_{2} \mathrm{O}_{2}$, hydrogen peroxide; $\mathrm{HOCl}$, hypochlorous acid; LC-MS/MS, liquid chromatography-tandem mass spectrometry; MDM2, mouse double minute 2 homolog; MMAC-1, mutated in multiple advanced cancers-1; mTORC1, mammalian target of rapamycin complex 1; mTORC2, mammalian target of rapamycin complex 2; CSNO, Snitrocysteine; OMFP, 3-O-methylfluorescein 6-phosphate; PD-motif, tyrosine/leucine/valine motif; PDK-1, protein kinase 1; PEST sequence. proline/serine/threonine/glutamic acid rich 
sequence; PFK2, phosphofructokinase-2; PH domain, plekstrin homology domain; P13K, phosphatidylinositol-3-kinase; $\quad \mathrm{PIP}_{2}, \quad$ phosphatidylinositol-4.5-phosphate; $\quad \mathrm{PIP}_{3}$, phosphatidylinositol-3,4,5-phosphate; pNPP, p-nitrophenyl phosphate; PPI, protein-protein interaction; PTB, phosphotyrosine domain; PTEN, phosphatase and tensin homolog; PTENa, phosphatase and tensin homolog alpha isoform; PTEN $\beta$, phosphatase and tensin homolog beta isoform; PTM, post-translational modification; PTP, protein tyrosine phosphatase; rDNA, ribosomal deoxyribonucleic acid; ROS, reactive oxygen species; RTK; receptor tyrosine kinase; SILAC, stable isotope labelling of amino acids in culture; SUMO, small ubiquitin-like modifier; TEP-1, tensin-like phosphatase-1; Trx, thioredoxin; TSC2, tuberous sclerosis complex 2; UPS, ubiquitin protease system; VHR, Vaccinia H1-related; Y2H, yeast 2-hybrid

\section{REFERENCES}

1. Li, D. M.; Sun, H., TEP1, encoded by a candidate tumor suppressor locus, is a novel protein tyrosine phosphatase regulated by transforming growth factor beta. Cancer Res 1997, 57 (11), 2124-9.

2. Li, J.; Yen, C.; Liaw, D.; Podsypanina, K.; Bose, S.; Wang, S. I.; Puc, J.; Miliaresis, C.; Rodgers, L.; McCombie, R.; Bigner, S. H.; Giovanella, B. C.; Ittmann, M.; Tycko, B.; Hibshoosh, H.; Wigler, M. H.; Parsons, R., PTEN, a putative protein tyrosine phosphatase gene mutated in human brain, breast, and prostate cancer. Science 1997, 275 (5308), 1943-1947.

3. $\quad$ Steck, P. A.; Pershouse, M. A.; Jasser, S. A.; Yung, W. K.; Lin, H.; Ligon, A. H.; Langford, L. A.; Baumgard, M. L.; Hattier, T.; Davis, T.; Frye, C.; Hu, R.; Swedlund, B.; Teng, D. H.; Tavtigian, S. V., Identification of a candidate tumour suppressor gene, MMAC1, at chromosome 10q23.3 that is mutated in multiple advanced cancers. Nat Genet 1997, 15 (4), 35662 .

4. Maehama, T.; Dixon, J. E., The tumor suppressor, PTEN/MMAC1, dephosphorylates the lipid second messenger, phosphatidylinositol 3,4,5-trisphosphate. Journal of Biological Chemistry 1998, 273 (22), 13375-13378.

5. $\quad$ Chen, C. Y.; Chen, J.; He, L.; Stiles, B. L., PTEN: Tumor Suppressor and Metabolic Regulator. Front Endocrinol (Lausanne) 2018, 9, 338.

6. Vazquez, F.; Grossman, S. R.; Takahashi, Y.; Rokas, M. V.; Nakamura, N.; Sellers, W. R., Phosphorylation of the PTEN tail acts as an inhibitory switch by preventing its recruitment into a protein complex. $J$ Biol Chem 2001, 276 (52), 48627-30. 
7. Lee, S. R.; Yang, K. S.; Kwon, J.; Lee, C.; Jeong, W.; Rhee, S. G., Reversible inactivation of the tumor suppressor PTEN by H2O2. Journal of Biological Chemistry 2002, 277 (23), 20336-20342.

8. Berggard, T.; Linse, S.; James, P., Methods for the detection and analysis of proteinprotein interactions. Proteomics 2007, 7 (16), 2833-42.

9. Mayer, B. J., Protein-protein interactions in signaling cascades. Molecular Biotechnology 1999, 13 (3), 201-213.

10. Phizicky, E. M.; Fields, S., Protein-protein interactions: methods for detection and analysis. Microbiol Rev 1995, 59 (1), 94-123.

11. Pawson, T., Specificity in Signal Transduction: From Phosphotyrosine-SH2 Domain Interactions to Complex Cellular Systems. Cell 2004, 116 (2), 191-203.

12. Spickett, C. M.; Pitt, A. R.; Morrice, N.; Kolch, W., Proteomic analysis of phosphorylation, oxidation and nitrosylation in signal transduction. Biochimica et Biophysica Acta (BBA) - Proteins and Proteomics 2006, 1764 (12), 1823-1841.

13. Westermarck, J.; Ivaska, J.; Corthals, G. L., Identification of protein interactions involved in cellular signaling. Mol Cell Proteomics 2013, 12 (7), 1752-63.

14. Jaeger, S.; Aloy, P., From protein interaction networks to novel therapeutic strategies. IUBMB Life 2012, 64 (6), 529-537.

15. von Mering, C.; Krause, R.; Snel, B.; Cornell, M.; Oliver, S. G.; Fields, S.; Bork, P., Comparative assessment of large-scale data sets of protein-protein interactions. Nature 2002, 417 (6887), 399-403.

16. Huang, H.; Jedynak, B. M.; Bader, J. S., Where Have All the Interactions Gone? Estimating the Coverage of Two-Hybrid Protein Interaction Maps. PLOS Computational Biology 2007, 3 (11), e214.

17. Zhang, B.; Park, B.-H.; Karpinets, T.; Samatova, N. F., From pull-down data to protein interaction networks and complexes with biological relevance. Bioinformatics 2008, 24 (7), 979986.

18. Brückner, A.; Polge, C.; Lentze, N.; Auerbach, D.; Schlattner, U., Yeast two-hybrid, a powerful tool for systems biology. Int J Mol Sci 2009, 10 (6), 2763-2788.

19. Mehla, J.; Caufield, J. H.; Sakhawalkar, N.; Uetz, P., Chapter Seventeen - A Comparison of Two-Hybrid Approaches for Detecting Protein-Protein Interactions. In Methods in Enzymology, Shukla, A. K., Ed. Academic Press: 2017; Vol. 586, pp 333-358.

20. Banks, C. A. S.; Boanca, G.; Lee, Z. T.; Florens, L.; Washburn, M. P., Proteins interacting with cloning scars: a source of false positive protein-protein interactions. Sci Rep 2015, 5, 8530-8530.

21. Tian, B.; Zhao, C.; Gu, F.; He, Z., A two-step framework for inferring direct proteinprotein interaction network from AP-MS data. BMC Systems Biology 2017, 11 (4), 82.

22. Peng, X.; Wang, J.; Peng, W.; Wu, F.-X.; Pan, Y., Protein-protein interactions: detection, reliability assessment and applications. Briefings in Bioinformatics 2016, 18 (5), 798819.

23. Yugandhar, K.; Gupta, S.; Yu, H., Inferring Protein-Protein Interaction Networks From Mass Spectrometry-Based Proteomic Approaches: A Mini-Review. Computational and Structural Biotechnology Journal 2019, 17, 805-811.

24. Xing, S.; Wallmeroth, N.; Berendzen, K. W.; Grefen, C., Techniques for the Analysis of Protein-Protein Interactions in Vivo. Plant Physiology 2016, 171 (2), 727. 
25. Hong, J.; Luo, Y.; Zhang, Y.; Ying, J.; Xue, W.; Xie, T.; Tao, L.; Zhu, F., Protein functional annotation of simultaneously improved stability, accuracy and false discovery rate achieved by a sequence-based deep learning. Briefings in Bioinformatics 2019, 21 (4), 14371447.

26. Yu, H.; Braun, P.; Yıldırım, M. A.; Lemmens, I.; Venkatesan, K.; Sahalie, J.; Hirozane-Kishikawa, T.; Gebreab, F.; Li, N.; Simonis, N.; Hao, T.; Rual, J.-F.; Dricot, A.; Vazquez, A.; Murray, R. R.; Simon, C.; Tardivo, L.; Tam, S.; Svrzikapa, N.; Fan, C.; de Smet, A.-S.; Motyl, A.; Hudson, M. E.; Park, J.; Xin, X.; Cusick, M. E.; Moore, T.; Boone, C.; Snyder, M.; Roth, F. P.; Barabási, A.-L.; Tavernier, J.; Hill, D. E.; Vidal, M., HighQuality Binary Protein Interaction Map of the Yeast Interactome Network. Science 2008, 322 (5898), 104.

27. Suthram, S.; Shlomi, T.; Ruppin, E.; Sharan, R.; Ideker, T., A direct comparison of protein interaction confidence assignment schemes. BMC Bioinformatics 2006, 7 (1), 360.

28. Lee, J. O.; Yang, H.; Georgescu, M. M.; Di Cristofano, A.; Maehama, T.; Shi, Y.; Dixon, J. E.; Pandolfi, P.; Pavletich, N. P., Crystal structure of the PTEN tumor suppressor: implications for its phosphoinositide phosphatase activity and membrane association. Cell 1999, 99 (3), 323-34.

29. Yuvaniyama, J.; Denu, J. M.; Dixon, J. E.; Saper, M. A., Crystal structure of the dual specificity protein phosphatase VHR. Science 1996, 272 (5266), 1328-31.

30. Denu, J. M.; Dixon, J. E., Protein tyrosine phosphatases: mechanisms of catalysis and regulation. Curr Opin Chem Biol 1998, 2 (5), 633-41.

31. Barford, D.; Das, A. K.; Egloff, M. P., The structure and mechanism of protein phosphatases: insights into catalysis and regulation. Annu Rev Biophys Biomol Struct 1998, 27, $133-64$.

32. Zhang, Z.-Y., Chemical and Mechanistic Approaches to the Study of Protein Tyrosine Phosphatases. Accounts of Chemical Research 2003, 36 (6), 385-392.

33. Xiao, Y.; Yeong Chit Chia, J.; Gajewski, J. E.; Sio Seng Lio, D.; Mulhern, T. D.; Zhu, H.-J.; Nandurkar, H.; Cheng, H.-C., PTEN catalysis of phospholipid dephosphorylation reaction follows a two-step mechanism in which the conserved aspartate-92 does not function as the general acid - Mechanistic analysis of a familial Cowden disease-associated PTEN mutation. Cellular Signalling 2007, 19 (7), 1434-1445.

34. Chia, J. Y.-C.; Gajewski, J. E.; Xiao, Y.; Zhu, H.-J.; Cheng, H.-C., Unique biochemical properties of the protein tyrosine phosphatase activity of PTEN-Demonstration of different active site structural requirements for phosphopeptide and phospholipid phosphatase activities of PTEN. Biochimica et Biophysica Acta (BBA) - Proteins and Proteomics 2010, 1804 (9), 17851795 .

35. Leitner, M. G.; Hobiger, K.; Mavrantoni, A.; Feuer, A.; Oberwinkler, J.; Oliver, D.; Halaszovich, C. R., A126 in the active site and TI167/168 in the TI loop are essential determinants of the substrate specificity of PTEN. Cellular and Molecular Life Sciences 2018, 75 (22), 4235-4250.

36. Nalefski, E. A.; Falke, J. J., The $\mathrm{C} 2$ domain calcium-binding motif: structural and functional diversity. Protein Sci 1996, 5 (12), 2375-90.

37. Rizo, J.; Sudhof, T. C., C2-domains, structure and function of a universal Ca2+-binding domain. J Biol Chem 1998, 273 (26), 15879-82.

38. Das, S.; Dixon, J. E.; Cho, W., Membrane-binding and activation mechanism of PTEN. Proceedings of the National Academy of Sciences 2003, 100 (13), 7491. 
39. Georgescu, M. M.; Kirsch, K. H.; Kaloudis, P.; Yang, H.; Pavletich, N. P.; Hanafusa, H., Stabilization and productive positioning roles of the $\mathrm{C} 2$ domain of PTEN tumor suppressor. Cancer Res 2000, 60 (24), 7033-8.

40. Malaney, P.; Pathak, R. R.; Xue, B.; Uversky, V. N.; Davé, V., Intrinsic Disorder in PTEN and its Interactome Confers Structural Plasticity and Functional Versatility. Sci Rep 2013, $3(1), 2035$.

41. Georgescu, M.; Kirsch, K.; Akagi, T.; Shishido, T.; Hanafusa, H., The tumorsuppressor activity of PTEN is regulated by its carboxy-terminal region. Proceedings of the National Academy of Sciences of the United States of America 1999, 96, 10182-7.

42. Rechsteiner, M.; Rogers, S. W., PEST sequences and regulation by proteolysis. Trends Biochem Sci 1996, 21 (7), 267-71.

43. Myers, M. P.; Stolarov, J. P.; Eng, C.; Li, J.; Wang, S. I.; Wigler, M. H.; Parsons, R.; Tonks, N. K., P-TEN, the tumor suppressor from human chromosome 10q23, is a dualspecificity phosphatase. Proc Natl Acad Sci U S A 1997, 94 (17), 9052-7.

44. Al-Khouri, A. M.; Ma, Y.; Togo, S. H.; Williams, S.; Mustelin, T., Cooperative Phosphorylation of the Tumor Suppressor Phosphatase and Tensin Homologue (PTEN) by Casein Kinases and Glycogen Synthase Kinase 3ß. Journal of Biological Chemistry 2005, 280 (42), 35195-35202.

45. Bolduc, D.; Rahdar, M.; Tu-Sekine, B.; Sivakumaren, S. C.; Raben, D.; Amzel, L. M.; Devreotes, P.; Gabelli, S. B.; Cole, P., Phosphorylation-mediated PTEN conformational closure and deactivation revealed with protein semisynthesis. eLife 2013, 2, e00691.

46. Masson, G. R.; Perisic, O.; Burke, J. E.; Williams, R. L., The intrinsically disordered tails of PTEN and PTEN-L have distinct roles in regulating substrate specificity and membrane activity. Biochemical Journal 2016, 473, 135-144.

47. Tibarewal, P.; Zilidis, G.; Spinelli, L.; Schurch, N.; Maccario, H.; Gray, A.; Perera, N. M.; Davidson, L.; Barton, G. J.; Leslie, N. R., PTEN Protein Phosphatase Activity Correlates with Control of Gene Expression and Invasion, a Tumor-Suppressing Phenotype, But Not with AKT Activity. Sci. Signal. 2012, 5 (213), ra18.

48. Fanning, A. S.; Anderson, J. M., PDZ domains: fundamental building blocks in the organization of protein complexes at the plasma membrane. J Clin Invest 1999, 103 (6), 767-72.

49. Teng, D. H.; Hu, R.; Lin, H.; Davis, T.; Iliev, D.; Frye, C.; Swedlund, B.; Hansen, K. L.; Vinson, V. L.; Gumpper, K. L.; Ellis, L.; El-Naggar, A.; Frazier, M.; Jasser, S.; Langford, L. A.; Lee, J.; Mills, G. B.; Pershouse, M. A.; Pollack, R. E.; Tornos, C.; Troncoso, P.; Yung, W. K.; Fujii, G.; Berson, A.; Steck, P. A.; et al., MMAC1/PTEN mutations in primary tumor specimens and tumor cell lines. Cancer Res 1997, 57 (23), 5221-5. 50. Lee, H.-J.; Zheng, J. J., PDZ domains and their binding partners: structure, specificity, and modification. Cell Communication and Signaling 2010, 8 (1), 8.

51. Sotelo, N. S.; Schepens, J. T. G.; Valiente, M.; Hendriks, W.; Pulido, R., PTEN-PDZ domain interactions: Binding of PTEN to PDZ domains of PTPN13. Methods 2015, 77-78, 147156.

52. $\quad$ Liang, H.; He, S.; Yang, J.; Jia, X.; Wang, P.; Chen, X.; Zhang, Z.; Zou, X.; McNutt, Michael A.; Shen, Wen H.; Yin, Y., PTEN\&\#x3b1; a PTEN Isoform Translated through Alternative Initiation, Regulates Mitochondrial Function and Energy Metabolism. Cell Metabolism 2014, 19 (5), 836-848.

53. Hopkins, B. D.; Fine, B.; Steinbach, N.; Dendy, M.; Rapp, Z.; Shaw, J.; Pappas, K.; Yu, J. S.; Hodakoski, C.; Mense, S.; Klein, J.; Pegno, S.; Sulis, M.-L.; Goldstein, H.; 
Amendolara, B.; Lei, L.; Maurer, M.; Bruce, J.; Canoll, P.; Hibshoosh, H.; Parsons, R., A Secreted PTEN Phosphatase That Enters Cells to Alter Signaling and Survival. Science 2013, 341 (6144), 399.

54. Liang, H.; Chen, X.; Yin, Q.; Ruan, D.; Zhao, X.; Zhang, C.; McNutt, M. A.; Yin, Y., $\mathrm{PTEN} \beta$ is an alternatively translated isoform of PTEN that regulates rDNA transcription. Nature Communications 2017, 8 (1), 14771.

55. Wang, L.; Cho, Y.-L.; Tang, Y.; Wang, J.; Park, J.-E.; Wu, Y.; Wang, C.; Tong, Y.; Chawla, R.; Zhang, J.; Shi, Y.; Deng, S.; Lu, G.; Wu, Y.; Tan, H. W.-S.; Pawijit, P.; Lim, G. G.-Y.; Chan, H.-Y.; Zhang, J.; Fang, L.; Yu, H.; Liou, Y.-C.; Karthik, M.; Bay, B.-H.; Lim, K.-L.; Sze, S.-K.; Yap, C. T.; Shen, H.-M., PTEN-L is a novel protein phosphatase for ubiquitin dephosphorylation to inhibit PINK1-Parkin-mediated mitophagy. Cell Research 2018, 28 (8), 787-802.

56. $\quad$ Ding, W.-X.; Yin, X.-M., Mitophagy: mechanisms, pathophysiological roles, and analysis. Biological Chemistry 2012, 393 (7), 547.

57. Sato, S.; Furuya, N., Induction of PINK1/Parkin-Mediated Mitophagy. In Mitophagy: Methods and Protocols, Hattori, N.; Saiki, S., Eds. Springer New York: New York, NY, 2018; pp 9-17.

58. Shen, S.-M.; Zhang, C.; Ge, M.-K.; Dong, S.-S.; Xia, L.; He, P.; Zhang, N.; Ji, Y.; Yang, S.; Yu, Y.; Zheng, J.-K.; Yu, J.-X.; Xia, Q.; Chen, G.-Q., PTEN $\alpha$ and PTEN $\beta$ promote carcinogenesis through WDR5 and H3K4 trimethylation. Nature Cell Biology 2019, 21 (11), 1436-1448.

59. Song, M. S.; Salmena, L.; Pandolfi, P. P., The functions and regulation of the PTEN tumour suppressor. Nature Reviews Molecular Cell Biology 2012, 13 (5), 283-296.

60. Lee, Y. R.; Chen, M.; Pandolfi, P. P., The functions and regulation of the PTEN tumour suppressor: new modes and prospects. Nature Reviews Molecular Cell Biology 2018, 19 (9), 547-562.

61. Hopkins, B. D.; Hodakoski, C.; Barrows, D.; Mense, S. M.; Parsons, R. E., PTEN function: the long and the short of it. Trends in Biochemical Sciences 2014, 39 (4), 183-190. 62. James, S. R.; Downes, P. C.; Gigg, R.; Grove, S. J. A.; Holmes, A. B.; Alessi, D. R., Specific binding of the Akt-1 protein kinase to phosphatidylinositol 3,4,5-trisphosphate without subsequent activation. Biochemical Journal 1996, 315 (3), 709-713.

63. Alessi, D. R.; James, S. R.; Downes, C. P.; Holmes, A. B.; Gaffney, P. R. J.; Reese, C. B.; Cohen, P., Characterization of a 3-phosphoinositide-dependent protein kinase which phosphorylates and activates protein kinase $\mathrm{B}<\mathrm{em}>\& \# \mathrm{x} 3 \mathrm{~b} 1 ;</ \mathrm{em}>$. Current Biology 1997, 7 (4), 261-269.

64. Stokoe, D.; Stephens, L. R.; Copeland, T.; Gaffney, P. R. J.; Reese, C. B.; Painter, G. F.; Holmes, A. B.; McCormick, F.; Hawkins, P. T., Dual Role of Phosphatidylinositol-3,4,5trisphosphate in the Activation of Protein Kinase B. Science 1997, 277 (5325), 567.

65. Alessi, D. R.; Andjelkovic, M.; Caudwell, B.; Cron, P.; Morrice, N.; Cohen, P.; Hemmings, B. A., Mechanism of activation of protein kinase B by insulin and IGF-1. The EMBO Journal 1996, 15 (23), 6541-6551.

66. Sarbassov, D. D.; Guertin, D. A.; Ali, S. M.; Sabatini, D. M., Phosphorylation and regulation of Akt/PKB by the rictor-mTOR complex. Science 2005, 307 (5712), 1098-1101. 67. Yang, J.; Cron, P.; Good, V. M.; Thompson, V.; Hemmings, B. A.; Barford, D., Crystal structure of an activated Akt/Protein Kinase B ternary complex with GSK3-peptide and AMP-PNP. Nature Structural Biology 2002, 9 (12), 940-944. 
68. Manning, B. D.; Cantley, L. C., AKT/PKB signaling: navigating downstream. Cell 2007, $129(7), 1261-74$.

69. Marte, B. M.; Downward, J., PKB/Akt: connecting phosphoinositide 3-kinase to cell survival and beyond. Trends Biochem Sci 1997, 22 (9), 355-8.

70. Stiles, B.; Gilman, V.; Khanzenzon, N.; Lesche, R.; Li, A.; Qiao, R.; Liu, X.; Wu, H., Essential role of AKT-1/protein kinase B alpha in PTEN-controlled tumorigenesis. Mol Cell Biol 2002, 22 (11), 3842-51.

71. Manning, B. D.; Toker, A., AKT/PKB Signaling: Navigating the Network. Cell 2017, 169 (3), 381-405.

72. Evangelisti, C.; Chiarini, F.; Paganelli, F.; Marmiroli, S.; Martelli, A. M., Crosstalks of GSK3 signaling with the mTOR network and effects on targeted therapy of cancer. Biochimica et Biophysica Acta (BBA) - Molecular Cell Research 2020, 1867 (4), 118635.

73. Sutherland, C.; Leighton, I. A.; Cohen, P., Inactivation of glycogen synthase kinase-3 $\beta$ by phosphorylation: new kinase connections in insulin and growth-factor signalling. Biochemical Journal 1993, 296 (1), 15-19.

74. Brunet, A.; Bonni, A.; Zigmond, M. J.; Lin, M. Z.; Juo, P.; Hu, L. S.; Anderson, M. J.; Arden, K. C.; Blenis, J.; Greenberg, M. E., Akt Promotes Cell Survival by Phosphorylating and Inhibiting a Forkhead Transcription Factor. Cell 1999, 96 (6), 857-868.

75. van der Vos, K. E.; Coffer, P. J., The Extending Network of FOXO Transcriptional Target Genes. Antioxid. Redox Signal. 2010, 14 (4), 579-592.

76. Saxton, R. A.; Sabatini, D. M., mTOR Signaling in Growth, Metabolism, and Disease. Cell 2017, 168 (6), 960-976.

77. Zhao, J.; Zhai, B.; Gygi, S. P.; Goldberg, A. L., mTOR inhibition activates overall protein degradation by the ubiquitin proteasome system as well as by autophagy. Proceedings of the National Academy of Sciences 2015, 112 (52), 15790.

78. Zilfou, J. T.; Lowe, S. W., Tumor Suppressive Functions of p53. Cold Spring Harbor Perspectives in Biology 2009, 1 (5), a001883-a001883.

79. Ogawara, Y.; Kishishita, S.; Obata, T.; Isazawa, Y.; Suzuki, T.; Tanaka, K.; Masuyama, N.; Gotoh, Y., Akt Enhances Mdm2-mediated Ubiquitination and Degradation of p53. Journal of Biological Chemistry 2002, 277 (24), 21843-21850.

80. Berkers, Celia R.; Maddocks, Oliver D. K.; Cheung, Eric C.; Mor, I.; Vousden, Karen H., Metabolic Regulation by p53 Family Members. Cell Metabolism 2013, 18 (5), 617633.

81. Novellasdemunt, L.; Tato, I.; Navarro-Sabate, A.; Ruiz-Meana, M.; Méndez-Lucas, A.; Perales, J. C.; Garcia-Dorado, D.; Ventura, F.; Bartrons, R.; Rosa, J. L., Akt-dependent Activation of the Heart 6-Phosphofructo-2-kinase/Fructose-2,6-bisphosphatase (PFKFB2) Isoenzyme by Amino Acids. Journal of Biological Chemistry 2013, 288 (15), 10640-10651.

82. Roberts, D. J.; Tan-Sah, V. P.; Smith, J. M.; Miyamoto, S., Akt Phosphorylates HK-II at Thr-473 and Increases Mitochondrial HK-II Association to Protect Cardiomyocytes. Journal of Biological Chemistry 2013, 288 (33), 23798-23806.

83. Cong, L.-N.; Chen, H.; Li, Y.; Zhou, L.; McGibbon, M. A.; Taylor, S. I.; Quon, M. J., Physiological Role of Akt in Insulin-Stimulated Translocation of GLUT4 in Transfected Rat Adipose Cells. Molecular Endocrinology 1997, 11 (13), 1881-1890.

84. Aparna, P.; Barber, T.; Bunt, M.; Rudge, S.; Zhang, Q.; Lachlan, K.; Cooper, N.; Linden, H.; Levy, J.; Wakelam, M.; Walker, L.; Karpe, F.; Gloyn, A., PTEN Mutations as a 
Cause of Constitutive Insulin Sensitivity and Obesity. The New England journal of medicine 2012, 367, 1002-11.

85. Myers, M. P.; Pass, I.; Batty, I. H.; Van der Kaay, J.; Stolarov, J. P.; Hemmings, B. A.; Wigler, M. H.; Downes, C. P.; Tonks, N. K., The lipid phosphatase activity of PTEN is critical for its tumor supressor function. Proc Natl Acad Sci U S A 1998, 95 (23), 13513-8. 86. Sun, H.; Lesche, R.; Li, D. M.; Liliental, J.; Zhang, H.; Gao, J.; Gavrilova, N.; Mueller, B.; Liu, X.; Wu, H., PTEN modulates cell cycle progression and cell survival by regulating phosphatidylinositol 3,4,5,-trisphosphate and Akt/protein kinase B signaling pathway. Proc Natl Acad Sci U S A 1999, 96 (11), 6199-204.

87. Liu, T.; Wang, Y.; Wang, Y.; Chan, A. M., Multifaceted Regulation of PTEN Subcellular Distributions and Biological Functions. Cancers (Basel) 2019, 11 (9), 1247. 88. Brito, M. B.; Goulielmaki, E.; Papakonstanti, E. A., Focus on PTEN regulation. Frontiers in Oncology 2015, 5.

89. Correia, N. C.; Girio, A.; Antunes, I.; Martins, L. R.; Barata, J. T., The multiple layers of non-genetic regulation of PTEN tumour suppressor activity. European Journal of Cancer 2014, 50 (1), 216-225.

90. Mirmohammadsadegh, A.; Marini, A.; Nambiar, S.; Hassan, M.; Tannapfel, A.; Ruzicka, T.; Hengge, U. R., Epigenetic Silencing of the PTEN Gene in Melanoma. Cancer Research 2006, 66 (13), 6546.

91. Leslie, N. R.; Bennett, D.; Lindsay, Y. E.; Stewart, H.; Gray, A.; Downes, C. P., Redox regulation of PI 3-kinase signalling via inactivation of PTEN. Embo j 2003, 22 (20), 5501-10.

92. Trotman, L. C.; Wang, X.; Alimonti, A.; Chen, Z.; Teruya-Feldstein, J.; Yang, H.; Pavletich, N. P.; Carver, B. S.; Cordon-Cardo, C.; Erdjument-Bromage, H.; Tempst, P.; Chi, S.-G.; Kim, H.-J.; Misteli, T.; Jiang, X.; Pandolfi, P. P., Ubiquitination Regulates PTEN Nuclear Import and Tumor Suppression. Cell 2007, 128 (1), 141-156.

93. Kwak, Y.-D.; Ma, T.; Diao, S.; Zhang, X.; Chen, Y.; Hsu, J.; Lipton, S. A.; Masliah, E.; Xu, H.; Liao, F.-F., NO signaling and S-nitrosylation regulate PTEN inhibition in neurodegeneration. Molecular Neurodegeneration 2010, 5 (1), 49.

94. De Melo, J.; He, L.; Tang, D., The Protein-Protein Interaction-Mediated Inactivation of PTEN. Curr. Mol. Med. 2014, 14 (1), 22-33.

95. Vazquez, F.; Sellers, W. R., The PTEN tumor suppressor protein: an antagonist of phosphoinositide 3-kinase signaling. Biochimica Et Biophysica Acta-Reviews on Cancer 2000, 1470 (1), M21-M35.

96. Silva, A.; Yunes, J. A.; Cardoso, B. A.; Martins, L. R.; Jotta, P. Y.; Abecasis, M.; Nowill, A. E.; Leslie, N. R.; Cardoso, A. A.; Barata, J. T., PTEN posttranslational inactivation and hyperactivation of the PI3K/Akt pathway sustain primary $\mathrm{T}$ cell leukemia viability. The Journal of Clinical Investigation 2008, 118 (11), 3762-3774.

97. Raftopoulou, M.; Etienne-Manneville, S.; Self, A.; Nicholls, S.; Hall, A., Regulation of cell migration by the C2 domain of the tumor suppressor PTEN. Science 2004, 303 (5661), 117981.

98. Torres, J.; Pulido, R., The tumor suppressor PTEN is phosphorylated by the protein kinase CK2 at its C terminus - Implications for PTEN stability to proteasome-mediated degradation. Journal of Biological Chemistry 2001, 276 (2), 993-998.

99. Guo, Y. J.; Pan, W. W.; Liu, S. B.; Shen, Z. F.; Xu, Y.; Hu, L. L., ERK/MAPK signalling pathway and tumorigenesis. Exp Ther Med 2020, 19 (3), 1997-2007. 
100. Verrastro, I.; Tveen-Jensen, K.; Spickett, C. M.; Pitt, A. R., The effect of HOCl-induced modifications on phosphatase and tensin homologue (PTEN) structure and function. Free Radic Res 2018, 52 (2), 232-247.

101. Roos, G.; Foloppe, N.; Messens, J., Understanding the $\mathrm{p} \mathrm{K}$ a of Redox Cysteines: The Key Role of Hydrogen Bonding. Antioxid. Redox Signal. 2012, 18.

102. Forman, H. J.; Torres, M., Reactive Oxygen Species and Cell Signaling. American Journal of Respiratory and Critical Care Medicine 2002, 166 (supplement_1), S4-S8.

103. Forman, H. J.; Fukuto, J. M.; Torres, M., Redox signaling: thiol chemistry defines which reactive oxygen and nitrogen species can act as second messengers. American Journal of Physiology-Cell Physiology 2004, 287 (2), C246-C256.

104. Sohn, J.; Rudolph, J., Catalytic and Chemical Competence of Regulation of Cdc25 Phosphatase by Oxidation/Reduction. Biochemistry 2003, 42 (34), 10060-10070.

105. Yu, C.-X.; Li, S.; Whorton, A. R., Redox Regulation of PTEN by $S$-Nitrosothiols. Molecular Pharmacology 2005, 68 (3), 847.

106. Lang, V.; Aillet, F.; Da Silva-Ferrada, E.; Xolalpa, W.; Zabaleta, L.; Rivas, C.; Rodriguez, M. S., Analysis of PTEN ubiquitylation and SUMOylation using molecular traps.

Methods 2015, 77-78, 112-118.

107. Wang, X.; Trotman, L. C.; Koppie, T.; Alimonti, A.; Chen, Z.; Gao, Z.; Wang, J.;

Erdjument-Bromage, H.; Tempst, P.; Cordon-Cardo, C.; Pandolfi, P. P.; Jiang, X., NEDD4-1 Is a Proto-Oncogenic Ubiquitin Ligase for PTEN. Cell 2007, 128 (1), 129-139.

108. Gupta, A.; Leslie, N. R., Controlling PTEN (Phosphatase and Tensin Homolog) Stability: A DOMINANT ROLE FOR LYSINE 66. Journal of Biological Chemistry 2016, 291 (35), 18465-18473.

109. Wendy, X.; Patricia, P.-G.; Manuel, S. R.; Gael, R., Targeting the Ubiquitin Proteasome System: Beyond Proteasome Inhibition. Current Pharmaceutical Design 2013, 19 (22), 40534093.

110. Huang, J.; Yan, J.; Zhang, J.; Zhu, S.; Wang, Y.; Shi, T.; Zhu, C.; Chen, C.; Liu, X.; Cheng, J.; Mustelin, T.; Feng, G.-S.; Chen, G.; Yu, J., SUMO1 modification of PTEN regulates tumorigenesis by controlling its association with the plasma membrane. Nature Communications 2012, 3 (1), 911.

111. Bassi, C.; Ho, J.; Srikumar, T.; Dowling, R. J. O.; Gorrini, C.; Miller, S. J.; Mak, T. W.; Neel, B. G.; Raught, B.; Stambolic, V., Nuclear PTEN Controls DNA Repair and Sensitivity to Genotoxic Stress. Science 2013, 341 (6144), 395.

112. González-Santamaría, J.; Campagna, M.; Ortega-Molina, A.; Marcos-Villar, L.; de la Cruz-Herrera, C. F.; González, D.; Gallego, P.; Lopitz-Otsoa, F.; Esteban, M.; Rodríguez, M. S.; Serrano, M.; Rivas, C., Regulation of the tumor suppressor PTEN by SUMO. Cell Death Dis. 2012, 3 (9), e393-e393.

113. Stark, C.; Breitkreutz, B. J.; Reguly, T.; Boucher, L.; Breitkreutz, A.; Tyers, M., BioGRID: a general repository for interaction datasets. Nucleic Acids Res 2006, 34 (Database issue), D535-9.

114. Orchard, S.; Ammari, M.; Aranda, B.; Breuza, L.; Briganti, L.; Broackes-Carter, F.; Campbell, N. H.; Chavali, G.; Chen, C.; del-Toro, N.; Duesbury, M.; Dumousseau, M.; Galeota, E.; Hinz, U.; Iannuccelli, M.; Jagannathan, S.; Jimenez, R.; Khadake, J.; Lagreid, A.; Licata, L.; Lovering, R. C.; Meldal, B.; Melidoni, A. N.; Milagros, M.; Peluso, D.; Perfetto, L.; Porras, P.; Raghunath, A.; Ricard-Blum, S.; Roechert, B.; Stutz, A.; Tognolli, M.; van Roey, K.; Cesareni, G.; Hermjakob, H., The MIntAct project--IntAct as a common 
curation platform for 11 molecular interaction databases. Nucleic Acids Res 2014, 42 (Database issue), D358-63.

115. Fields, S., High-throughput two-hybrid analysis. The FEBS Journal 2005, 272 (21), 5391-5399.

116. Schoeters, F.; Munro, C. A.; d'Enfert, C.; Van Dijck, P., A High-Throughput Candida albicans Two-Hybrid System. mSphere 2018, 3 (4), e00391-18.

117. Holmgren, A., Antioxidant Function of Thioredoxin and Glutaredoxin Systems. Antioxid. Redox Signal. 2000, 2 (4), 811-820.

118. Meuillet, E. J.; Mahadevan, D.; Berggren, M.; Coon, A.; Powis, G., Thioredoxin-1 binds to the $\mathrm{C} 2$ domain of PTEN inhibiting PTEN's lipid phosphatase activity and membrane binding: a mechanism for the functional loss of PTEN's tumor suppressor activity. Archives of Biochemistry and Biophysics 2004, 429 (2), 123-133.

119. Schwertassek, U.; Haque, A.; Krishnan, N.; Greiner, R.; Weingarten, L.; Dick, T. P.; Tonks, N. K., Reactivation of oxidized PTP1B and PTEN by thioredoxin 1. The FEBS Journal 2014, 281 (16), 3545-3558.

120. Song, Z.; Saghafi, N.; Gokhale, V.; Brabant, M.; Meuillet, E. J., Regulation of the activity of the tumor suppressor PTEN by thioredoxin in Drosophila melanogaster. Experimental Cell Research 2007, 313 (6), 1161-1171.

121. Sadeghirizi, A.; Yazdanparast, R.; Aghazadeh, S., Combating trastuzumab resistance by targeting thioredoxin-1/PTEN interaction. Tumor Biology 2016, 37 (5), 6737-6747.

122. Neumann, C. A.; Cao, J.; Manevich, Y., Peroxiredoxin 1 and its role in cell signaling. Cell Cycle 2009, 8 (24), 4072-4078.

123. Cao, J.; Schulte, J.; Knight, A.; Leslie, N. R.; Zagozdzon, A.; Bronson, R.; Manevich, Y.; Beeson, C.; Neumann, C. A., Prdx1 inhibits tumorigenesis via regulating PTEN/AKT activity. Embo j 2009, 28 (10), 1505-17.

124. Le Naour, F.; Misek, D. E.; Krause, M. C.; Deneux, L.; Giordano, T. J.; Scholl, S.; Hanash, S. M., Proteomics-based identification of RS/DJ-1 as a novel circulating tumor antigen in breast cancer. Clin Cancer Res 2001, 7 (11), 3328-35.

125. MacKeigan, J. P.; Clements, C. M.; Lich, J. D.; Pope, R. M.; Hod, Y.; Ting, J. P., Proteomic profiling drug-induced apoptosis in non-small cell lung carcinoma: identification of RS/DJ-1 and RhoGDIalpha. Cancer Res 2003, 63 (20), 6928-34.

126. Kim, R. H.; Peters, M.; Jang, Y.; Shi, W.; Pintilie, M.; Fletcher, G. C.; DeLuca, C.; Liepa, J.; Zhou, L.; Snow, B.; Binari, R. C.; Manoukian, A. S.; Bray, M. R.; Liu, F.-F.; Tsao, M.-S.; Mak, T. W., DJ-1, a novel regulator of the tumor suppressor PTEN. Cancer Cell 2005, 7 (3), 263-273.

127. Lin, Y.; Chen, Q.; Liu, Q.-X.; Zhou, D.; Lu, X.; Deng, X.-f.; Yang, H.; Zheng, H.; Qiu, Y., High expression of DJ-1 promotes growth and invasion via the PTEN-AKT pathway and predicts a poor prognosis in colorectal cancer. Cancer Medicine 2018, 7 (3), 809-819. 128. Gorbenko, O.; Kuznetsov, V.; Kukharenko, O.; Zhyvoloup, A.; Panasyuk, G.; Nemazanyy, I.; Filonenko, V.; Gout, I., Identification of a novel binding partners for tumor suppressor PTEN by a yeast two-hybrid approach. Eksp Onkol 2004, 26 (1), 15-9.

129. Gorbenko, O.; Panayotou, G.; Zhyvoloup, A.; Volkova, D.; Gout, I.; Filonenko, V., Identification of novel PTEN-binding partners: PTEN interaction with fatty acid binding protein FABP4. Mol Cell Biochem 2010, 337 (1-2), 299-305. 
130. Crockett, D. K.; Fillmore, G. C.; Elenitoba-Johnson, K. S.; Lim, M. S., Analysis of phosphatase and tensin homolog tumor suppressor interacting proteins by in vitro and in silico proteomics. Proteomics 2005, 5 (5), 1250-62.

131. Herlevsen, M.; Oxford, G.; Ptak, C.; Shabanowitz, J.; Hunt, D. F.; Conaway, M.; Theodorescu, D., A novel model to identify interaction partners of the PTEN tumor suppressor gene in human bladder cancer. Biochem. Biophys. Res. Commun. 2007, 352 (2), 549-555.

132. Gunaratne, J.; Goh, M. X.; Swa, H. L.; Lee, F. Y.; Sanford, E.; Wong, L. M.; Hogue, K. A.; Blackstock, W. P.; Okumura, K., Protein interactions of phosphatase and tensin homologue (PTEN) and its cancer-associated G20E mutant compared by using stable isotope labeling by amino acids in cell culture-based parallel affinity purification. J Biol Chem 2011, 286 (20), 18093-103.

133. Maddika, S.; Kavela, S.; Rani, N.; Palicharla, V. R.; Pokorny, J. L.; Sarkaria, J. N.; Chen, J., WWP2 is an E3 ubiquitin ligase for PTEN. Nat Cell Biol 2011, 13 (6), 728-33.

134. Verrastro, I.; Tveen-Jensen, K.; Woscholski, R.; Spickett, C. M.; Pitt, A. R., Reversible oxidation of phosphatase and tensin homolog (PTEN) alters its interactions with signaling and regulatory proteins. Free Radic Biol Med 2016, 90, 24-34.

135. Ahn, Y.; Hwang, Chae Y.; Lee, S.-R.; Kwon, K.-S.; Lee, C., The tumour suppressor PTEN mediates a negative regulation of the E3 ubiquitin-protein ligase Nedd4. Biochemical Journal 2008, 412 (2), 331-338.

136. Chen, T. C.; Lin, K. T.; Chen, C. H.; Lee, S. A.; Lee, P. Y.; Liu, Y. W.; Kuo, Y. L.; Wang, F. S.; Lai, J. M.; Huang, C. Y., Using an in situ proximity ligation assay to systematically profile endogenous protein-protein interactions in a pathway network. J Proteome Res 2014, 13 (12), 5339-46.

137. Kumar, P.; Munnangi, P.; Chowdary, K. R.; Shah, V. J.; Shinde, S. R.; Kolli, N. R.; Halehalli, R. R.; Nagarajaram, H. A.; Maddika, S., A Human Tyrosine Phosphatase Interactome Mapped by Proteomic Profiling. J Proteome Res 2017, 16 (8), 2789-2801.

138. Li, Z.; Ivanov, A. A.; Su, R.; Gonzalez-Pecchi, V.; Qi, Q.; Liu, S.; Webber, P.; McMillan, E.; Rusnak, L.; Pham, C.; Chen, X.; Mo, X.; Revennaugh, B.; Zhou, W.; Marcus, A.; Harati, S.; Chen, X.; Johns, M. A.; White, M. A.; Moreno, C.; Cooper, L. A.; Du, Y.; Khuri, F. R.; Fu, H., The OncoPPi network of cancer-focused protein-protein interactions to inform biological insights and therapeutic strategies. Nat Commun 2017, 8, 14356.

139. Song, M. S.; Carracedo, A.; Salmena, L.; Song, S. J.; Egia, A.; Malumbres, M.; Pandolfi, P. P., Nuclear PTEN regulates the APC-CDH1 tumor-suppressive complex in a phosphatase-independent manner. Cell 2011, 144 (2), 187-99.

140. Shen, J. P.; Zhao, D.; Sasik, R.; Luebeck, J.; Birmingham, A.; Bojorquez-Gomez, A.; Licon, K.; Klepper, K.; Pekin, D.; Beckett, A. N.; Sanchez, K. S.; Thomas, A.; Kuo, C. C.; Du, D.; Roguev, A.; Lewis, N. E.; Chang, A. N.; Kreisberg, J. F.; Krogan, N.; Qi, L.; Ideker, T.; Mali, P., Combinatorial CRISPR-Cas9 screens for de novo mapping of genetic interactions. Nat Methods 2017, 14 (6), 573-576.

141. Han, K.; Jeng, E. E.; Hess, G. T.; Morgens, D. W.; Li, A.; Bassik, M. C., Synergistic drug combinations for cancer identified in a CRISPR screen for pairwise genetic interactions. Nat Biotechnol 2017, 35 (5), 463-474.

142. Vizeacoumar, F. J.; Arnold, R.; Vizeacoumar, F. S.; Chandrashekhar, M.; Buzina, A.; Young, J. T.; Kwan, J. H.; Sayad, A.; Mero, P.; Lawo, S.; Tanaka, H.; Brown, K. R.; Baryshnikova, A.; Mak, A. B.; Fedyshyn, Y.; Wang, Y.; Brito, G. C.; Kasimer, D.; Makhnevych, T.; Ketela, T.; Datti, A.; Babu, M.; Emili, A.; Pelletier, L.; Wrana, J.; 
Wainberg, Z.; Kim, P. M.; Rottapel, R.; O'Brien, C. A.; Andrews, B.; Boone, C.; Moffat, J., A negative genetic interaction map in isogenic cancer cell lines reveals cancer cell vulnerabilities. Mol Syst Biol 2013, 9, 696.

143. Louche, A.; Salcedo, S. P.; Bigot, S., Protein-Protein Interactions: Pull-Down Assays. Methods Mol Biol 2017, 1615, 247-255.

144. Aebersold, R.; Mann, M., Mass-spectrometric exploration of proteome structure and function. Nature 2016, 537 (7620), 347-355.

145. Rigaut, G.; Shevchenko, A.; Rutz, B.; Wilm, M.; Mann, M.; Seraphin, B., A generic protein purification method for protein complex characterization and proteome exploration. Nat Biotechnol 1999, 17 (10), 1030-2.

146. Ong, S. E.; Blagoev, B.; Kratchmarova, I.; Kristensen, D. B.; Steen, H.; Pandey, A.; Mann, M., Stable isotope labeling by amino acids in cell culture, SILAC, as a simple and accurate approach to expression proteomics. Mol Cell Proteomics 2002, 1 (5), 376-86.

147. Smits, A. H.; Vermeulen, M., Characterizing Protein-Protein Interactions Using Mass Spectrometry: Challenges and Opportunities. Trends in Biotechnology 2016, 34 (10), 825-834. 148. Kristensen, A. R.; Gsponer, J.; Foster, L. J., A high-throughput approach for measuring temporal changes in the interactome. Nature Methods 2012, 9 (9), 907-909.

149. Havugimana, Pierre C.; Hart, G. T.; Nepusz, T.; Yang, H.; Turinsky, Andrei L.; Li, Z.; Wang, Peggy I.; Boutz, Daniel R.; Fong, V.; Phanse, S.; Babu, M.; Craig, Stephanie A.; Hu, P.; Wan, C.; Vlasblom, J.; Dar, V.-u.-N.; Bezginov, A.; Clark, Gregory W.; Wu, Gabriel C.; Wodak, Shoshana J.; Tillier, Elisabeth R. M.; Paccanaro, A.; Marcotte, Edward M.; Emili, A., A Census of Human Soluble Protein Complexes. Cell 2012, 150 (5), 1068-1081.

150. Deng, J.; Erdjument-Bromage, H.; Neubert, T. A., Quantitative Comparison of Proteomes Using SILAC. Curr Protoc Protein Sci 2019, 95 (1), e74.

151. Formosa, T.; Barry, J.; Alberts, B. M.; Greenblatt, J., Using protein affinity chromatography to probe structure of protein machines. Methods Enzymol 1991, 208, 24-45. 152. Ong, S.-E.; Kratchmarova, I.; Mann, M., Properties of 13C-Substituted Arginine in Stable Isotope Labeling by Amino Acids in Cell Culture (SILAC). J. Proteome Res. 2003, 2 (2), 173-181.

153. Mann, M., Functional and quantitative proteomics using SILAC. Nature Reviews Molecular Cell Biology 2006, 7 (12), 952-958.

154. Rao, V. S.; Srinivas, K.; Sujini, G. N.; Kumar, G. N., Protein-protein interaction detection: methods and analysis. International Journal of Proteomics 2014, 147648.

155. Adelmant, G.; Garg, B. K.; Tavares, M.; Card, J. D.; Marto, J. A., Tandem Affinity Purification and Mass Spectrometry (TAP-MS) for the Analysis of Protein Complexes. Curr Protoc Protein Sci 2019, 96 (1), e84.

156. Kimple, M. E.; Brill, A. L.; Pasker, R. L., Overview of affinity tags for protein purification. Current protocols in protein science 2013, 73, 9.9.1-9.9.23.

157. Kabuyama, Y.; Nakatsu, N.; Homma, Y.; Fukui, Y., Purification and characterization of the phosphatidylinositol-3,4,5-trisphosphate phosphatase in bovine thymus. Eur J Biochem 1996, 238 (2), 350-6.

158. Arora, N.; Ghosh, S. S., Functional characterizations of interactive recombinant PTENsilica nanoparticles for potential biomedical applications. RSC Advances 2016, 6 (115), 114944114954.

159. Mak, L. H.; Woscholski, R., Targeting PTEN using small molecule inhibitors. Methods 2015, 77-78, 63-8. 
160. Morris, J. H.; Knudsen, G. M.; Verschueren, E.; Johnson, J. R.; Cimermancic, P.; Greninger, A. L.; Pico, A. R., Affinity purification-mass spectrometry and network analysis to understand protein-protein interactions. Nat Protoc 2014, 9 (11), 2539-2554.

161. Strokach, A.; Corbi-Verge, C.; Teyra, J.; Kim, P. M., Predicting the Effect of Mutations on Protein Folding and Protein-Protein Interactions. Methods Mol Biol 2019, 1851, 1-17.

162. Duan, G.; Walther, D., The Roles of Post-translational Modifications in the Context of Protein Interaction Networks. PLOS Computational Biology 2015, 11 (2), e1004049.

163. Collins, M. O.; Choudhary, J. S., Mapping multiprotein complexes by affinity purification and mass spectrometry. Current Opinion in Biotechnology 2008, 19 (4), 324-330.

164. Xu, X.; Song, Y.; Li, Y.; Chang, J.; zhang, H.; An, L., The tandem affinity purification method: An efficient system for protein complex purification and protein interaction identification. Protein Expression and Purification 2010, 72 (2), 149-156.

165. Kaake, R. M.; Wang, X.; Huang, L., Profiling of Protein Interaction Networks of Protein Complexes Using Affinity Purification and Quantitative Mass Spectrometry. Molecular \&amp;amp; Cellular Proteomics 2010, 9 (8), 1650.

166. Fields, S.; Song, O., A novel genetic system to detect protein-protein interactions. Nature 1989, 340 (6230), 245-6.

167. Keegan, L.; Gill, G.; Ptashne, M., Separation of DNA binding from the transcriptionactivating function of a eukaryotic regulatory protein. Science 1986, 231 (4739), 699.

168. Caufield, J. H.; Sakhawalkar, N.; Uetz, P., A comparison and optimization of yeast twohybrid systems. Methods (San Diego, Calif.) 2012, 58 (4), 317-324.

169. Mosessian, S.; Wu, H., PTEN-Associated Complexes: An Overview. Curr Top Biochem Res 2010, 12 (1), 37-42.

170. Collins, B. C.; Gillet, L. C.; Rosenberger, G.; Röst, H. L.; Vichalkovski, A.; Gstaiger, M.; Aebersold, R., Quantifying protein interaction dynamics by SWATH mass spectrometry: application to the 14-3-3 system. Nature Methods 2013, 10 (12), 1246-1253.

171. Snider, J.; Kotlyar, M.; Saraon, P.; Yao, Z.; Jurisica, I.; Stagljar, I., Fundamentals of protein interaction network mapping. Molecular Systems Biology 2015, 11 (12), 848.

172. Milella, M.; Falcone, I.; Conciatori, F.; Cesta Incani, U.; Del Curatolo, A.; Inzerilli, N.; Nuzzo, C. M. A.; Vaccaro, V.; Vari, S.; Cognetti, F.; Ciuffreda, L., PTEN: Multiple Functions in Human Malignant Tumors. Frontiers in oncology 2015, 5, 24-24.

173. Gu, W.; Gaeta, X.; Sahakyan, A.; Chan, Alanna B.; Hong, Candice S.; Kim, R.; Braas, D.; Plath, K.; Lowry, William E.; Christofk, Heather R., Glycolytic Metabolism Plays a Functional Role in Regulating Human Pluripotent Stem Cell State. Cell Stem Cell 2016, 19 (4), 476-490.

174. Ghandi, M.; Huang, F. W.; Jané-Valbuena, J.; Kryukov, G. V.; Lo, C. C.; McDonald, E. R., 3rd; Barretina, J.; Gelfand, E. T.; Bielski, C. M.; Li, H.; Hu, K.; Andreev-Drakhlin, A. Y.; Kim, J.; Hess, J. M.; Haas, B. J.; Aguet, F.; Weir, B. A.; Rothberg, M. V.; Paolella, B. R.; Lawrence, M. S.; Akbani, R.; Lu, Y.; Tiv, H. L.; Gokhale, P. C.; de Weck, A.; Mansour, A. A.; Oh, C.; Shih, J.; Hadi, K.; Rosen, Y.; Bistline, J.; Venkatesan, K.; Reddy, A.; Sonkin, D.; Liu, M.; Lehar, J.; Korn, J. M.; Porter, D. A.; Jones, M. D.; Golji, J.; Caponigro, G.;

Taylor, J. E.; Dunning, C. M.; Creech, A. L.; Warren, A. C.; McFarland, J. M.; Zamanighomi, M.; Kauffmann, A.; Stransky, N.; Imielinski, M.; Maruvka, Y. E.; Cherniack, A. D.;

Tsherniak, A.; Vazquez, F.; Jaffe, J. D.; Lane, A. A.; Weinstock, D. M.; Johannessen, C. M.; Morrissey, M. P.; Stegmeier, F.; Schlegel, R.; Hahn, W. C.; Getz, G.; Mills, G. B.; Boehm, J. 
S.; Golub, T. R.; Garraway, L. A.; Sellers, W. R., Next-generation characterization of the Cancer Cell Line Encyclopedia. Nature 2019, 569 (7757), 503-508.

175. Huttlin, E. L.; Bruckner, R. J.; Navarrete-Perea, J.; Cannon, J. R.; Baltier, K.; Gebreab, F.; Gygi, M. P.; Thornock, A.; Zarraga, G.; Tam, S.; Szpyt, J.; Panov, A.; Parzen, H.; Fu, S.; Golbazi, A.; Maenpaa, E.; Stricker, K.; Thakurta, S. G.; Rad, R.; Pan, J.; Nusinow, D. P.; Paulo, J. A.; Schweppe, D. K.; Vaites, L. P.; Harper, J. W.; Gygi, S. P., Dual Proteome-scale Networks Reveal Cell-specific Remodeling of the Human Interactome. bioRxiv 2020, 2020.01.19.905109.

176. Worby, C. A.; Dixon, J. E., PTEN. In Annual Review of Biochemistry, Vol 83, Kornberg, R. D., Ed. 2014; Vol. 83, pp 641-669.

177. McLoughlin, N. M.; Mueller, C.; Grossmann, T. N., The Therapeutic Potential of PTEN Modulation: Targeting Strategies from Gene to Protein. Cell Chem Biol 2018, 25 (1), 19-29.

178. Rotin, D.; Kumar, S., Physiological functions of the HECT family of ubiquitin ligases. Nature Reviews Molecular Cell Biology 2009, 10 (6), 398-409.

179. Li, H.; Zhang, P.; Zhang, Q.; Li, C.; Zou, W.; Chang, Z.; Cui, C.-P.; Zhang, L., WWP2 is a physiological ubiquitin ligase for phosphatase and tensin homolog (PTEN) in mice. Journal of Biological Chemistry 2018, 293 (23), 8886-8899.

180. Fouladkou, F.; Landry, T.; Kawabe, H.; Neeb, A.; Lu, C.; Brose, N.; Stambolic, V.; Rotin, D., The ubiquitin ligase Nedd4-1 is dispensable for the regulation of PTEN stability and localization. Proceedings of the National Academy of Sciences 2008, 105 (25), 8585.

181. Chen, Z.; Thomas, S. N.; Bolduc, D. M.; Jiang, X.; Zhang, X.; Wolberger, C.; Cole, P. A., Enzymatic Analysis of PTEN Ubiquitylation by WWP2 and NEDD4-1 E3 Ligases.

Biochemistry 2016, 55 (26), 3658-66.

182. Smith, I. N.; Briggs, J. M., Structural mutation analysis of PTEN and its genotypephenotype correlations in endometriosis and cancer. Proteins 2016, 84 (11), 1625-1643.

183. Yabe, D.; Nakamura, T.; Kanazawa, N.; Tashiro, K.; Honjo, T., Calumenin, a Ca2+binding protein retained in the endoplasmic reticulum with a novel carboxyl-terminal sequence, HDEF. J Biol Chem 1997, 272 (29), 18232-9.

184. Zhang, Y.; Park, J.; Han, S.-J.; Yang, S. Y.; Yoon, H. J.; Park, I.; Woo, H. A.; Lee, S.-R., Redox regulation of tumor suppressor PTEN in cell signaling. Redox Biology 2020, 34, 101553.

185. Kim, Y. C.; Kitaura, H.; Taira, T.; Iguchi-Ariga, S. M.; Ariga, H., Oxidation of DJ-1dependent cell transformation through direct binding of DJ-1 to PTEN. Int J Oncol 2009, 35 (6), 1331-41.

186. Berggren, M. I.; Husbeck, B.; Samulitis, B.; Baker, A. F.; Gallegos, A.; Powis, G., Thioredoxin Peroxidase-1 (peroxiredoxin-1) Is Increased in Thioredoxin-1 Transfected Cells and Results in Enhanced Protection against Apoptosis Caused by Hydrogen Peroxide but Not by Other Agents Including Dexamethasone, Etoposide, and Doxorubicin. Archives of Biochemistry and Biophysics 2001, 392 (1), 103-109.

187. Madureira, P. A.; Hill, R.; Miller, V. A.; Giacomantonio, C.; Lee, P. W.; Waisman, D. M., Annexin A2 is a novel cellular redox regulatory protein involved in tumorigenesis.

Oncotarget 2011, 2 (12), 1075-93.

188. Castaldo, S. A.; Ajime, T.; Serrão, G.; Anastácio, F.; Rosa, J. T.; Giacomantonio, C. A.; Howarth, A.; Hill, R.; Madureira, P. A., Annexin A2 Regulates AKT Upon $\mathrm{H}_{2} \mathrm{O}_{2}-$ Dependent Signaling Activation in Cancer Cells. Cancers (Basel) 2019, 11 (4), 492. 
For TOC Only

\begin{tabular}{|c|c|c|}
\hline $\begin{array}{l}\text { Y2H \& DNA } \\
\text { Sequencing }\end{array}$ & + & $\begin{array}{c}\text { APD \& } \\
\text { LC-MS/MS }\end{array}$ \\
\hline $\begin{array}{l}\text { Wild Type } \\
\text { PTEN }\end{array}$ & & $\begin{array}{c}\text { PTEN's } \\
\text { Phosphatase } \\
\text { Activity }\end{array}$ \\
\hline $\begin{array}{l}\text { Mutated } \\
\text { PTEN }\end{array}$ & 'TEN & $\begin{array}{c}\text { PTEN } \\
\text { Degradation }\end{array}$ \\
\hline $\begin{array}{l}\text { Oxidised } \\
\text { PTEN }\end{array}$ & & $\begin{array}{c}\text { PTEN's } \\
\text { cellular } \\
\text { localisation }\end{array}$ \\
\hline
\end{tabular}




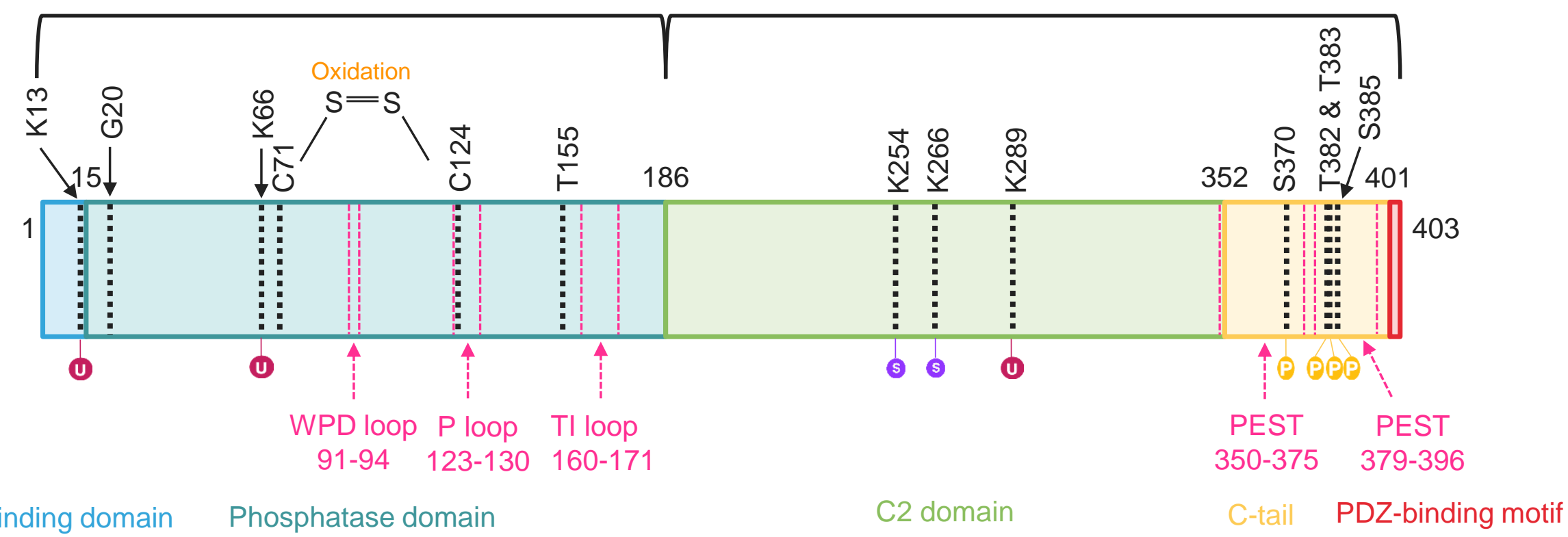

Figure 1: The $\mathrm{N}$ - and $\mathrm{C}$ - terminal domains of PTEN. The modular structure of PTEN shows N-terminal and C-terminal domains. The Nterminal $\mathrm{PIP}_{2}$ binding domain (blue) contains $\mathrm{K} 13$, which can be modified by ubiquitinylation (U). The phosphatase domain (dark green) contains the WPD loop, P loop and TI loop. Within the phosphatase domain is the resolving C71 and catalytic C124, which on oxidation form a disulfide bond. Two resides, G20 and T55, are mutated in two of the high-data content studies included in this review. The C2 domain (green) contains K254, K266 and K289 which are amino acids modified by ubiquitinylation (U) and SUMOylation (S). The Cterminal tail (yellow) contains two PEST sequences, as well as four residues which can be modified by phosphorylation (P); S370, T382, T383 and S385. The PDZ-binding motif is shown in red. 


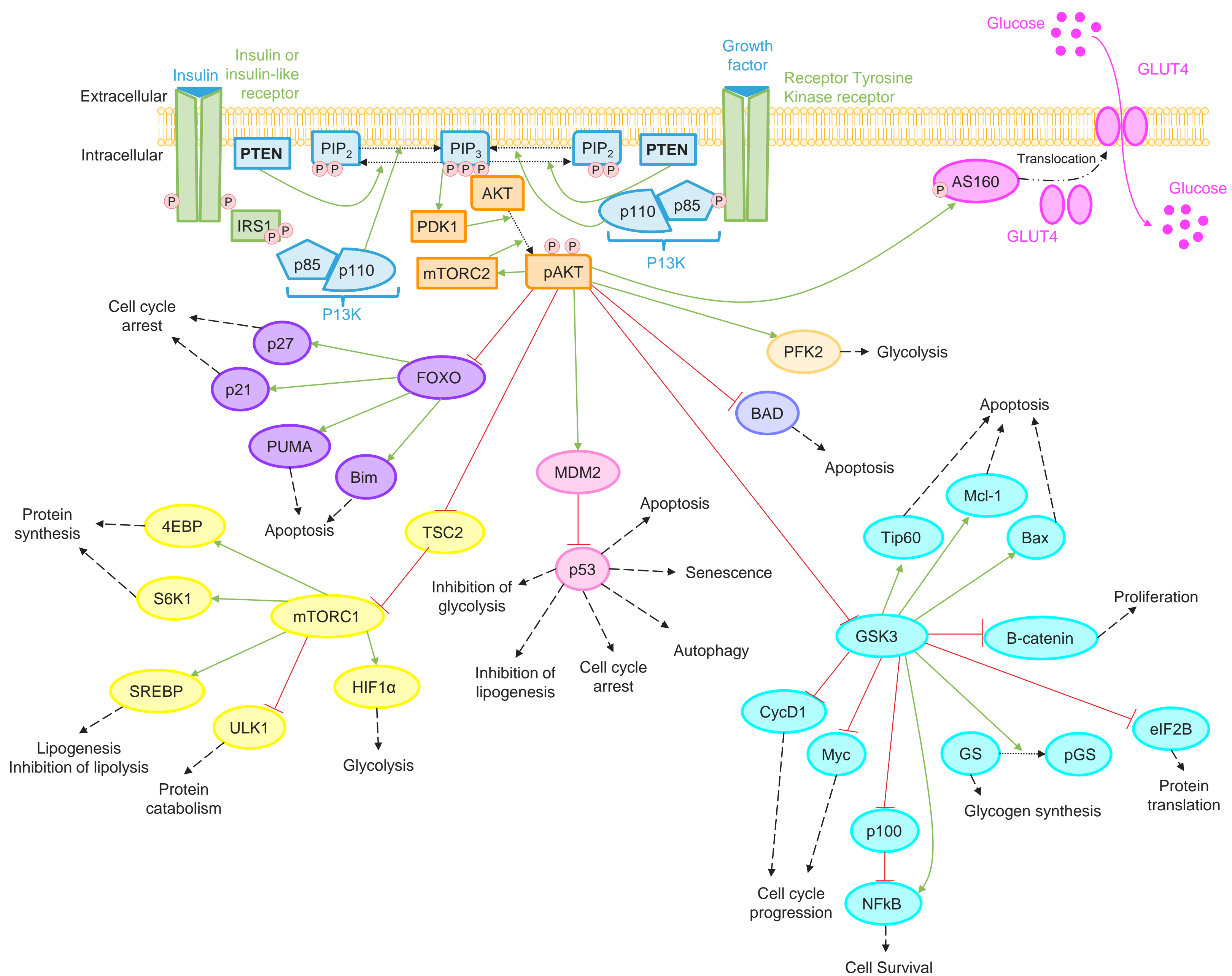




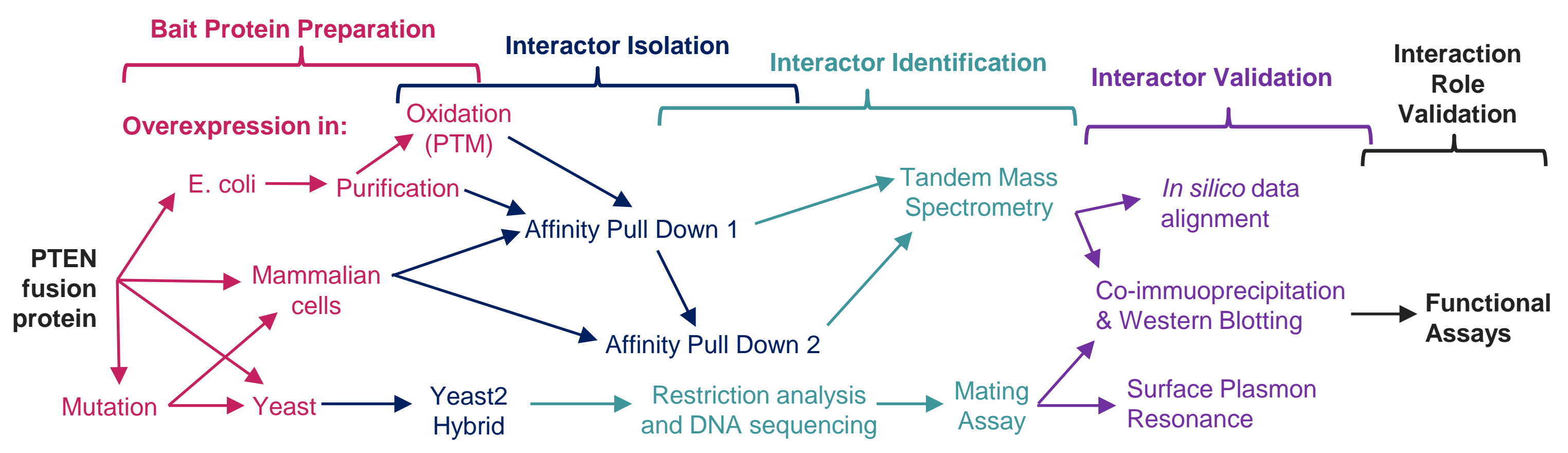

Figure 3. Pathways used in the 8 high data-content investigations into the interactome of PTEN. Once the PTEN fusion protein has been expressed in bait protein preparation and PTMs such as oxidation introduced if required (pink), protein-protein interactors can be isolated (dark blue) and identified (light blue). A small subset of these identified protein-protein interactors can be validated (purple) and for an even smaller subset a functional role may be proposed (black). 


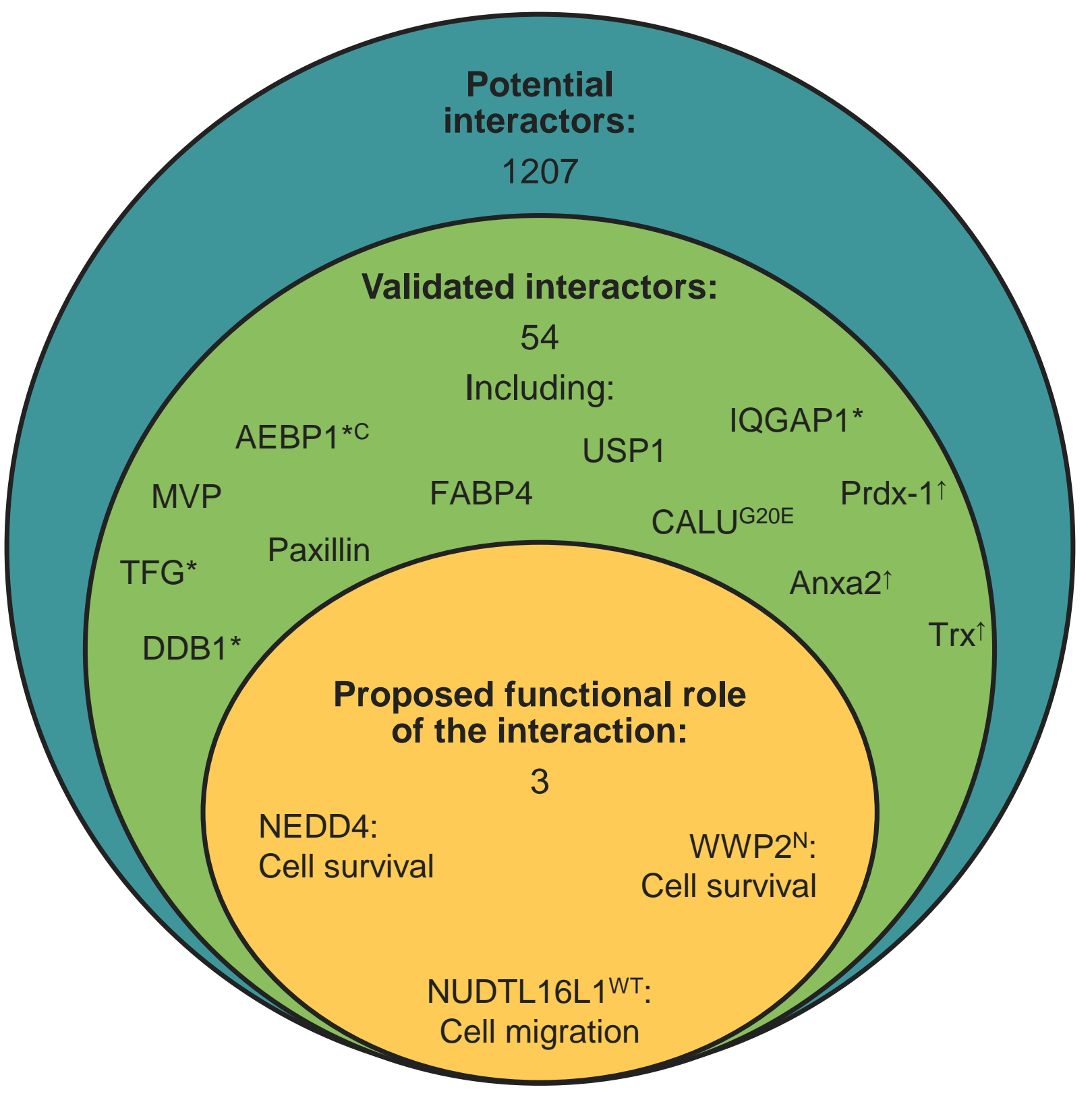

Figure 4: The validated interactors of PTEN and the proposed roles of those interactions. Key: *: a novel PTEN interactor; $\uparrow$ : an interactor with increased binding to oxidised PTEN; C: an interactor shown to bind to PTEN's C-terminal domain; $\mathrm{N}$ : an interactor shown to bind to PTEN's N-terminal domain; G20E: an interactor specific for the G20E PTEN mutant; WT: an interactor specific for wild-type PTEN, not the G20E mutant. 